\title{
Significant and Inevitable End-of-Twenty-First-Century Advances in Surface Runoff Timing in California's Sierra Nevada
}

\author{
MARla SCHWARTZ AND AlEX HALL \\ Department of Atmospheric and Oceanic Sciences, University of California, Los Angeles, Los Angeles, California \\ FENGPENG SUN \\ Department of Geosciences, University of Missouri-Kansas City, Kansas City, Missouri, and Department of \\ Atmospheric and Oceanic Sciences, University of California, Los Angeles, Los Angeles, California \\ DANiEl WALton AND NeIl Berg \\ Department of Atmospheric and Oceanic Sciences, University of California, Los Angeles, Los Angeles, California
}

(Manuscript received 31 October 2016, in final form 2 August 2017)

\begin{abstract}
Using hybrid dynamical-statistical downscaling, 3-km-resolution end-of-twenty-first-century runoff timing changes over California's Sierra Nevada for all available global climate models (GCMs) from phase 5 of the Coupled Model Intercomparison Project (CMIP5) are projected. All four representative concentration pathways (RCPs) adopted by the Intergovernmental Panel on Climate Change's Fifth Assessment Report are examined. These multimodel, multiscenario projections allow for quantification of ensemble-mean runoff timing changes and an associated range of possible outcomes due to both intermodel variability and choice of forcing scenario. Under a "business as usual" forcing scenario (RCP8.5), warming leads to a shift toward much earlier snowmelt-driven surface runoff in 2091-2100 compared to 1991-2000, with advances of as much as 80 days projected in the 35 -model ensemble mean. For a realistic "mitigation" scenario (RCP4.5), the ensemble-mean change is smaller but still large (up to 30 days). For all plausible forcing scenarios and all GCMs, the simulated changes are statistically significant, so that a detectable change in runoff timing is inevitable. Even for the mitigation scenario, the ensemble-mean change is approximately equivalent to one standard deviation of the natural variability at most elevations. Thus, even when greenhouse gas emissions are curtailed, the runoff change is climatically significant. For the business-as-usual scenario, the ensemble-mean change is approximately two standard deviations of the natural variability at most elevations, portending a truly dramatic change in surface hydrology by the century's end if greenhouse gas emissions continue unabated.
\end{abstract}

\section{Introduction}

Over half of California's developed water comes from small streams in the ecologically sensitive Sierra Nevada (SN; USDA Forest Service 2009). Understanding future streamflow changes in this region is therefore critical to ensuring enough freshwater resources for humans and ecosystems in the coming decades. Recent warming has already produced detectable changes in the timing, magnitude, and variability of SN streamflow (Aguado et al. 1992; Dettinger and Cayan 1995; Cayan et al. 2001; Regonda et al. 2005; Stewart et al. 2005; McCabe and

Corresponding author: Marla Schwartz, marla@atmos.ucla.edu
Clark 2005; Maurer 2007; Hidalgo et al. 2009; Kim and Jain 2010). Stewart et al. (2005) found that from 1948 to 2000 , a majority of SN rivers exhibited earlier timing of roughly 10-30 days during the snowmelt season. McCabe and Clark (2005) found a similar result for 84 streamflow gauges in the western United States, with increased April-July temperatures largely accounting for the advancement of runoff timing at most sites. Finally, Cayan et al. (2001) found that the first major pulse of snowmelt at high-elevation stream gauges in the western United States advanced by about 10 days between 1948 and 1995.

While observed shifts in SN runoff timing have been well documented, few studies have produced quantitative 
estimates of its future changes and associated uncertainty. One reason for this is that runoff timing in this region is influenced by a complex interplay of climatic and geographic factors that are poorly resolved in coarseresolution $(\sim 100 \mathrm{~km})$ global climate models (GCMs). GCMs lack important spatial structure in local climatic factors that are dominant controls on runoff timing and its spatial distribution, such as temperature $T$ and snowpack. Additionally, GCM resolution is too low to adequately represent physical watershed characteristics (e.g., elevation, slope, and vegetation type and coverage) that can also profoundly influence runoff timing and its spatial distribution.

These limitations have motivated efforts to regionalize GCM climate change signals through a variety of downscaling methods (Giorgi et al. 1994; Snyder et al. 2002; Timbal et al. 2003; Hayhoe et al. 2004; Leung et al. 2004; Duffy et al. 2006; Cabré et al. 2010; Salathé et al. 2010; Pierce et al. 2013). In this study, we rely on dynamical downscaling to simulate SN hydroclimate. We use a high-resolution regional climate model (RCM) to explicitly simulate complex finescale physical processes (Caldwell et al. 2009; Salathé et al. 2008, 2010; Arritt and Rummukainen 2011; Pierce et al. 2013). Our RCM framework resolves much of SN's finescale topography, the associated orographic precipitation $P$, and demarcations between solid and liquid forms of $P$. These processes are crucial for accurate representations of accumulated wintertime snowpack and spring/summertime runoff. Moreover, the RCM more credibly simulates the strength of the snow albedo feedback (SAF) over high elevations, which has an intricate spatial structure and is also a critical influence on local warming and runoff timing.

Previous studies have used RCMs to project future runoff timing changes in the SN. Rauscher et al. (2008) used the International Centre for Theoretical Physics Regional Climate Model (RegCM3; Pal et al. 2007) to investigate future changes in snowmelt-driven runoff over the western United States under the A2 emissions scenario (as described in the Special Report on Emissions Scenarios; Nakićenović and Swart 2000). They found that increases in January-March $T$ of approximately $3^{\circ}-5^{\circ} \mathrm{C}$ could cause runoff to occur as much as 2 months earlier in the late twenty-first century compared to a baseline period (1961-89). Future runoff timing projections in Rauscher et al. (2008) are only for a small number of GCMs, yielding limited information about most-likely outcomes and the associated model spread. This study also relied on a single forcing scenario, making it impossible to evaluate the consequences of societal choices regarding future greenhouse gas emissions.
Regionalizing a large number of GCM simulations is necessary to quantify ensemble-mean and uncertainty statistics for a single forcing scenario, let alone multiple forcing scenarios. However, this is impractical because of the high computational cost of RCMs. This shortcoming of RCMs highlights the need to develop a technique to project high-resolution future runoff timing in a way that fully samples the GCMs and forcing scenarios without a heavy computational burden. Stewart et al. (2004) provide an example of a more computationally feasible method using a statistically based technique, that is, relying on regression equations describing relationships among historical $P, T$, and runoff timing to project future runoff timing. However, they present results for only one climate model under one forcing scenario. Moreover, as with nearly all statistical techniques, their reliance on relationships derived from historical variability involves the so-called "stationarity" assumption, which may not be valid: it is possible those relationships may not hold in the future, especially for sustained changes in $T$ that far exceed those observed during the historical period.

The lack of a high-resolution multimodel, multiscenario analysis of end-of-twenty-first-century runoff timing changes over the $\mathrm{SN}$ serves as the primary motivation for this study. Here is a brief overview of our technique. First, we produce a historical or "baseline" simulation for the region by dynamically downscaling reanalysis data covering the final decade of the twentieth century. Next, five GCMs from phase 5 of the Coupled Model Intercomparison Project (CMIP5; Taylor et al. 2012) are dynamically downscaled under the representative concentration pathway 8.5 (RCP8.5) forcing scenario (van Vuuren et al. 2011). Then, output from the dynamical simulations is used to build a simple statistical model of runoff timing that emulates the dynamical model behavior. This model takes advantage of dynamical downscaling's physical credibility but is computationally efficient, allowing us to produce a large ensemble of runoff timing projections. Using the statistical model, we project runoff timing changes for all available CMIP5 models and forcing scenarios associated with the IPCC Fifth Assessment Report (van Vuuren et al. 2011). This allows for quantification of ensemble-mean future runoff timing changes in the $\mathrm{SN}$ and its associated uncertainty due to intermodel GCM spread, as well as the consequences associated with choice of forcing scenarios. Thus, we can assess the degree to which runoff timing changes occur no matter which model or forcing scenario is chosen and are therefore inevitable. Through comparison of the climate change signals with natural variability in the baseline simulation, we can also assess the statistical and climatic significance of the change signals. Because our technique involves both dynamical and statistical 
(a) WRF domains

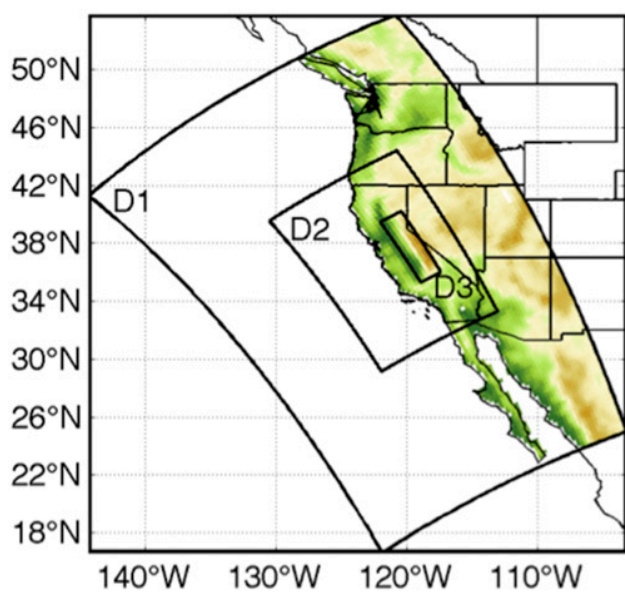

(b) Innermost domain (3-km) topography (m)

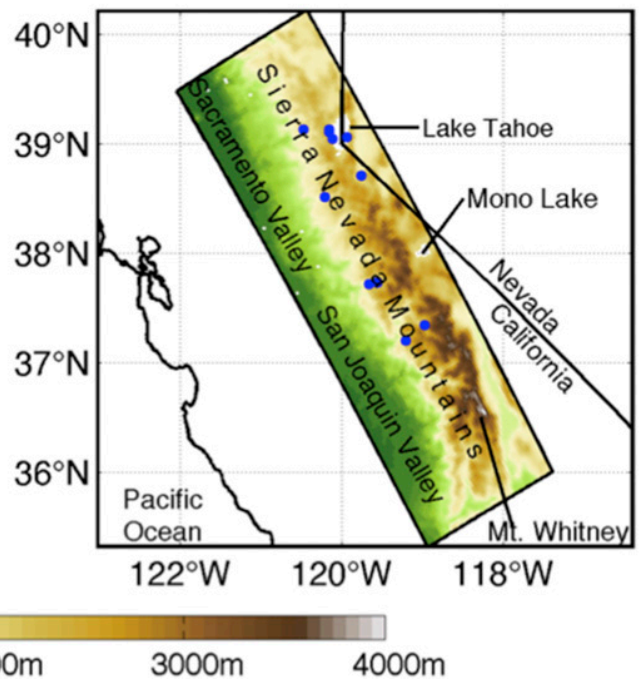

FIG. 1. (a) Model setup, with three nested WRF domains at resolutions of 27, 9, and $3 \mathrm{~km}$ (from the outermost to innermost domain). Topography $(\mathrm{m})$ is shown at the resolution of the $27-\mathrm{km}$ domain in color, and black lines show boundaries for U.S. states. (b) Topography $(\mathrm{m})$ of the innermost domain (3-km resolution) of the regional simulation, with the state borders of California and Nevada in black. Blue circles show the locations of 11 USGS HCDN-2009 streamflow gauges used for model evaluation.

downscaling, we call it hybrid dynamical-statistical downscaling, or simply hybrid downscaling.

This paper is organized as follows. Section 2 describes the dynamical downscaling model configuration, provides an observational evaluation of its performance, and presents dynamically downscaled end-of-twenty-firstcentury changes to runoff timing. Section 3 describes the statistical runoff timing model and its evaluation. Section 4 describes statistically based runoff timing projections for the full CMIP5 GCM ensemble for all forcing scenarios. This section quantifies ensemble-mean runoff timing changes, ranges due to intermodel variability, and consequences stemming from choice of forcing scenario. Section 5 contains a discussion of the importance of SAF to the results and compares the runoff timing changes projected in this study to those associated with other downscaled data products that do not include SAF. Finally, section 6 summarizes the major findings of this study and their implications.

\section{Dynamical model setup, evaluation, and results}

\section{a. Dynamical model setup}

Dynamical downscaling is performed using the Weather Research and Forecasting (WRF) Model version 3.5 (Skamarock et al. 2008), using the same model framework as Walton et al. (2017, hereinafter W2017). WRF is coupled to the community Noah land surface model with multiparameterization options (Noah-MP; Niu et al. 2011). Three one-way nested domains are used to represent the complex topography of California and the SN (Fig. 1a). The outermost domain spans the entire U.S. West Coast and adjacent Pacific Ocean at 27-km horizontal resolution. The middle domain, at 9-km resolution, covers all of California. The innermost domain, at 3-km resolution, spans the eastern edge of the Central Valley to the leeside of the California SN (Fig. 1b); this domain is the focus of this study.

In each domain, all variables within five grid cells from the horizontal lateral boundary are relaxed toward the corresponding values at the boundaries. To provide a better representation of surface and boundary layer processes, the model's vertical resolution is enhanced near the surface, with 30 out of 43 total sigma levels below $3 \mathrm{~km}$. WRF parameterization testing was done to optimize the model's performance in hydroclimate simulations, with the aim of improving the realism of simulated SN snowpack and streamflow processes. We chose the following physical parameterizations: the new Thompson microphysics scheme (Thompson et al. 2008), Dudhia shortwave radiation scheme (Dudhia 1989), Rapid Radiative Transfer Model (RRTM) longwave radiation scheme (Mlawer et al. 1997), MellorYamada-Nakanishi-Niino (MYNN) level 2.5 surface/ boundary layer scheme (Nakanishi and Niino 2006), and the old Kain-Fritsch cumulus convection scheme (Kain and Fritsch 1990). Spectral nudging of temperature, 
zonal and meridional winds, and geopotential height is employed above the boundary layer (roughly $850 \mathrm{hPa}$ ) over the outermost $27-\mathrm{km}$-resolution domain.

Climate change signals are produced from a single baseline simulation and five future simulations. The baseline simulation spans October 1991-September 2001 (water years 1992-2001, hereinafter WY 1992-2001) and is a dynamical downscaling of the National Centers for Environmental Prediction's 6-hourly North America Regional Reanalysis (NARR; Mesinger et al. 2006). NARR is a relatively coarse-resolution $(32 \mathrm{~km})$ reanalysis dataset that provides lateral boundary forcings and initial conditions for the outermost WRF domain in Fig. 1a. The baseline simulation allows us to evaluate the model's ability to simulate regional runoff timing through a comparison to observational data (section $2 \mathrm{~b}$ ) and serves as a climate state against which we can compare future climate simulations to measure change.

Using the same model configuration as the baseline, we perform a five-member ensemble of dynamical downscaling experiments to simulate a future end-of-twentyfirst-century climate. The simulations go from October 2091 to September 2101 (water years 2092-2101, hereinafter $\left.\mathrm{WY}_{2092-2101}\right)$. We dynamically downscale GCM experiments forced by RCP8.5. Out of all available CMIP5 GCMs forced by RCP8.5, we select five (CNRM-CM5, GFDL CM3, INM-CM4.0.0, IPSLCM5A-LR, and MPI-ESM-LR). These GCMs approximately sample the range of end-of-twenty-first-century near-surface $T$ and $P$ changes over California (see Fig. 2 of W2017).

To produce boundary conditions for the future WRF simulations, we add a perturbation reflecting the mean change in GCM climatology to NARR data for $\mathrm{WY}_{1992-2001}$, following Schär et al. (1996), Hara et al. (2008), Kawase et al. (2009), and Rasmussen et al. (2011). To calculate these GCM climate changes, we first quantify the differences in GCM monthly climatology between the historical and RCP8.5 experiments (2081-2100 average minus 1981-2000 average). Differences are calculated for temperature, humidity, zonal and meridional winds, and geopotential height. Then, for each of the five dynamically downscaled GCMs, we perturb the baseline 6-hourly NARR reanalysis data for each month by the corresponding monthly mean climatological change. The perturbed NARR fields then serve as WRF boundary conditions for five future climate simulations. This method allows us to assess how WY ${ }_{1992-2001}$ would transpire if the mean climate were altered to reflect the climate changes projected by each of the five GCMs. It allows us to quantify how the climate change signals simulated in the GCMs are expressed at the regional scale,

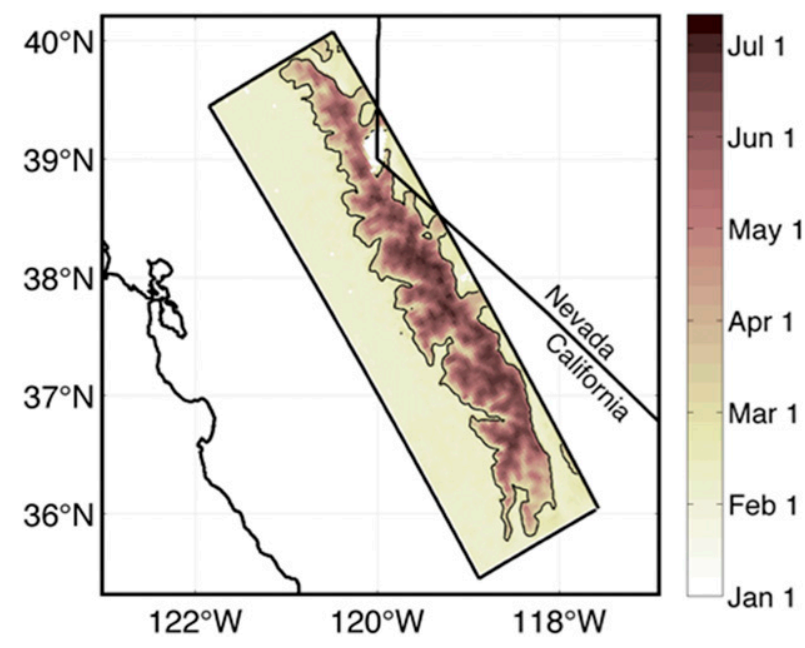

FIG. 2. Baseline (from October 1991 to September 2001) climatological date of $R_{50}$, which represents the date in the WY (1 Oct-30 Sep) by which $50 \%$ of the cumulative surface runoff has occurred. The black contour outlines grid points with climatological $R_{50}$ occurring on or after 1 Mar.

without the future simulations being subject to significant biases in mean state often found in GCMs. For additional information on model setup, parameterizations, and design of future simulations, the reader is referred to W2017.

\section{b. Baseline runoff timing climatology and model evaluation}

We first evaluate WRF's ability to simulate surface runoff timing during the baseline period. As a measure of runoff timing, we consider the date in the water year (from 1 October to 30 September; WY) by which $50 \%$ of the cumulative WY surface runoff has occurred $\left(R_{50}\right)$. Parameter $R_{50}$ is widely used as a metric of snowmelt timing (Regonda et al. 2005; Moore et al. 2007; Rauscher et al. 2008; Hidalgo et al. 2009; Wenger et al. 2010; Ashfaq et al. 2013). It is similar to the center timing of streamflow used in Stewart et al. (2004), Stewart et al. (2005), and McCabe and Clark (2005), but is found to be less sensitive to outliers in streamflow (Moore et al. 2007). Moreover, Regonda et al. (2005) suggest that $R_{50}$ is a more reliable indicator of snowmelt timing (in its relation to climatic variability and change) than the day of peak flow. In this paper, we use $R_{50}$ both for model evaluation and as a metric to diagnose future changes to runoff timing.

Figure 2 presents the baseline (WY $\mathrm{W}_{1992-2001}$ ) climatological date of $R_{50}$ in the $3-\mathrm{km}$ domain (seen in Fig. 1b). Climatological $R_{50}$ generally occurs after 1 March throughout the SN and shifts to even later in the WY as both elevation and the fraction of 
TABLE 1. Summary of information associated with observational streamflow gauges from the USGS HCDN-2009 used to evaluate the baseline simulation.

\begin{tabular}{|c|c|c|c|c|c|}
\hline ID & Station name & Hydrologic unit code & Latitude & Longitude & Drainage area $\left(\mathrm{km}^{2}\right)$ \\
\hline 10308200 & $\begin{array}{l}\text { East Fork Carson River below Markleeville } \\
\text { Creek }\end{array}$ & 16050201 & 38.714 & -119.764 & 716.4 \\
\hline 10336645 & General Creek near Meeks Bay, CA & 16050101 & 39.051 & -120.118 & 19.6 \\
\hline 10336660 & Blackwood Creek near Tahoe City, CA & 16050101 & 39.107 & -120.162 & 29.8 \\
\hline 10336676 & $\begin{array}{l}\text { Ward Creek at State Highway 89, near Tahoe } \\
\text { Pines, CA }\end{array}$ & 16050101 & 39.132 & -120.157 & 24.7 \\
\hline 10336740 & Logan House Creek near Glenbrook, NV & 16050101 & 39.066 & -119.935 & 5.5 \\
\hline 11230500 & Bear Creek near Lake Thomas A. Edison, CA & 18040006 & 37.339 & -118.973 & 135.5 \\
\hline 11237500 & Pitman Creek below Tamarack Creek, CA & 18040006 & 37.198 & -119.213 & 59.8 \\
\hline 11264500 & $\begin{array}{l}\text { Merced River at Happy Isles Bridge, near } \\
\text { Yosemite, CA }\end{array}$ & 18040008 & 37.731 & -119.558 & 468.0 \\
\hline 11266500 & $\begin{array}{l}\text { Merced River at Pohono Bridge, near } \\
\text { Yosemite, CA }\end{array}$ & 18040008 & 37.716 & -119.666 & 833.1 \\
\hline 11315000 & Cole Creek near Salt Springs Dam, CA & 18040012 & 38.519 & -120.212 & 54.0 \\
\hline 11427700 & $\begin{array}{l}\text { Duncan Canyon Creek near French } \\
\text { Meadows, CA }\end{array}$ & 18020128 & 39.135 & -120.478 & 25.5 \\
\hline
\end{tabular}

precipitation falling as snow $S / P$ increase. At lower elevations in the northern $\mathrm{SN}$ where the annual $S / P$ (not shown) ranges from 0.6 to 0.8 , climatological $R_{50}$ generally occurs before the start of summer. However, mid- to high elevations over the central and southern SN have a higher $S / P$ ratio $(0.8-0.95)$, which leads to snowmelt-driven surface runoff throughout the summer months, pushing back climatological $R_{50}$. For example, $R_{50}$ in the mountains just southwest of Mono Lake typically occurs as late as the beginning of July. Throughout the Central Valley, Owens Valley, and western Great Basin Desert along the CaliforniaNevada border, annual $P$ is low, and any $P$ typically falls as rain $(S / P<0.2)$. So surface runoff timing matches $P$ timing.

For this study, we consider surface runoff timing changes at locations where surface runoff is mostly generated by snowmelt. The 1 March $R_{50}$ cutoff date segregates snowfall-dominated grid points from raindominated regions or locations with minute climatological $P$. The black contour in Fig. 2 denotes locations with climatological baseline $R_{50}$ occurring on or after 1 March, indicating snowmelt-dominated runoff. The average baseline climatological $S / P$ within the contoured region is 0.86 , also indicative of a snowfalldominated regime. Within the contoured region in Fig. 2, the median and mean climatological percentages of total water-year runoff occurring from April to July are $78 \%$ and $69 \%$, respectively. This is consistent with other snowmelt-dominated watersheds in western North America examined by Stewart et al. (2005). We consider only grid points with climatological baseline $R_{50}$ on or after 1 March for the rest of the study. We also exclude inland water locations in our analyses. From here forward, the term "domain average" shall refer to an average over this restricted zone.

The dynamical model's ability to reproduce runoff timing variations during the baseline period can be assessed by comparing simulated $R_{50}$ to observations obtained from the U.S. Geological Survey (USGS) Hydro-Climatic Data Network 2009 (USGS HCDN-2009, https://waterdata.usgs.gov/nwis). The USGS HCDN-2009 is a network of streamflow gauges having the following characteristics: 1) natural streamflow least affected by direct human activities, 2) accurate measurement records, and 3) at least 20 years of complete and continuous records through WY 2009 (Slack et al. 1993; Lins 2012). We obtained daily, quality-controlled streamflow data from 11 stations for which data were available within our study domain for the baseline period. The station locations are indicated in Fig. $1 \mathrm{~b}$ with blue circles, and information associated with each station is summarized in Table 1 . The 11 stations represent a variety of elevations, drainage areas, and USGS eight-digit hydrologic unit codes across SN creeks and rivers.

The scatterplot in Fig. 3 presents observed versus simulated climatological $R_{50}$ for each of the 11 stations. Simulated climatological $R_{50}$ is taken to be the average $R_{50}$ of the grid points upstream of a gauge within that gauge's USGS hydrologic unit. This is equivalent to assuming instantaneous transport of water from the grid cell to the stream gauge location. A portion of the biases in this evaluation is likely due to this admittedly primitive river routing scheme. Each gauge's data point is also colored by the corresponding interannual correlation coefficient. For each gauge, simulated $R_{50}$ is well correlated with the observed $R_{50}$, 


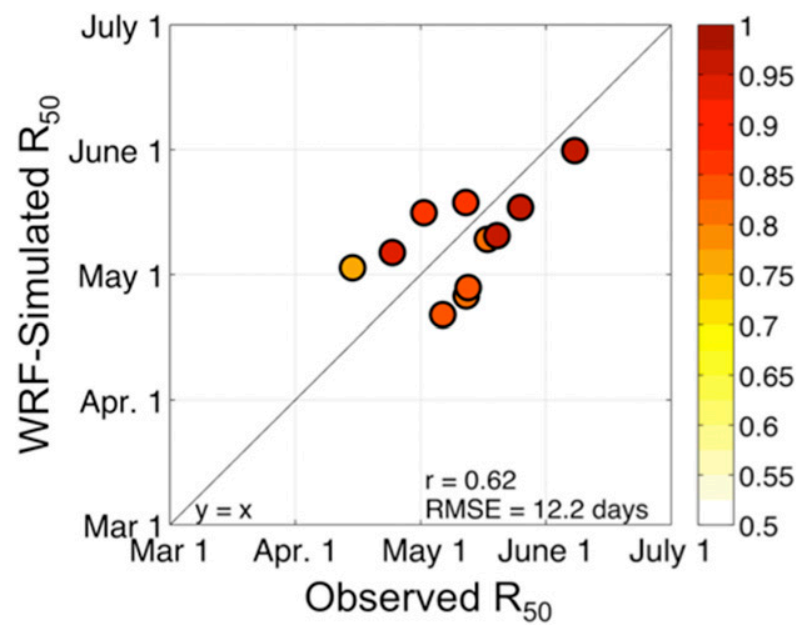

FIG. 3. Observed vs WRF-simulated climatological $R_{50}$ at 11 USGS streamflow gauges $\left(\mathrm{WY}_{1992-2001}\right)$. Simulated $R_{50}$ is estimated as the average $R_{50}$ of grid points upstream of a gauge within its watershed. Colors indicate the correlation coefficient between the time series of WRF-simulated and observed values of $R_{50}$. The line $y=x$ is shown in black.

with temporal $r$ ranging from 0.75 to 0.96 . (The gauge average is 0.87 .) The root-mean-square error between observed and simulated climatological $R_{50}$ is 12.2 days. Overall, the degree of agreement between simulated and observed $R_{50}$ dates indicates that the dynamical model is able to capture the main features of spatial and temporal $R_{50}$ variability across the $\mathrm{SN}$. In section 3, we also evaluate the realism of the dynamical model's sensitivity of $R_{50}$ to spring temperatures, a key parameter of the statistical model we develop to project future $R_{50}$.

\section{c. Dynamically downscaled changes in runoff timing}

Figures $4 \mathrm{a}-\mathrm{e}$ present the dynamically downscaled WRF end-of-twenty-first-century change (WY $\mathrm{W}_{2092-2101}$ minus $\left.\mathrm{WY}_{1992-2001}\right)$ in $R_{50}\left(\Delta R_{50}\right)$ under the RCP8.5 forcing scenario for the five GCMs. For all simulations, advances in $R_{50}$ are projected at all locations with substantial climatological baseline snowmelt-driven surface runoff. GFDL CM3 (Fig. 4b) and IPSLCM5A-LR (Fig. 4d) project the largest advances, with domain-average advances greater than 60 days. Advances in domain-average mean $R_{50}$ for CNRM-CM5 (Fig. 4a) and INM-CM4.0 (Fig. 4c) are smaller, but are still nearly 6 weeks earlier. These advances are similar in magnitude to those projected by Rauscher et al. (2008), yet a straightforward comparison is rather hard to obtain because of differences in model framework, including spatial resolutions, time periods, and downscaling methods.

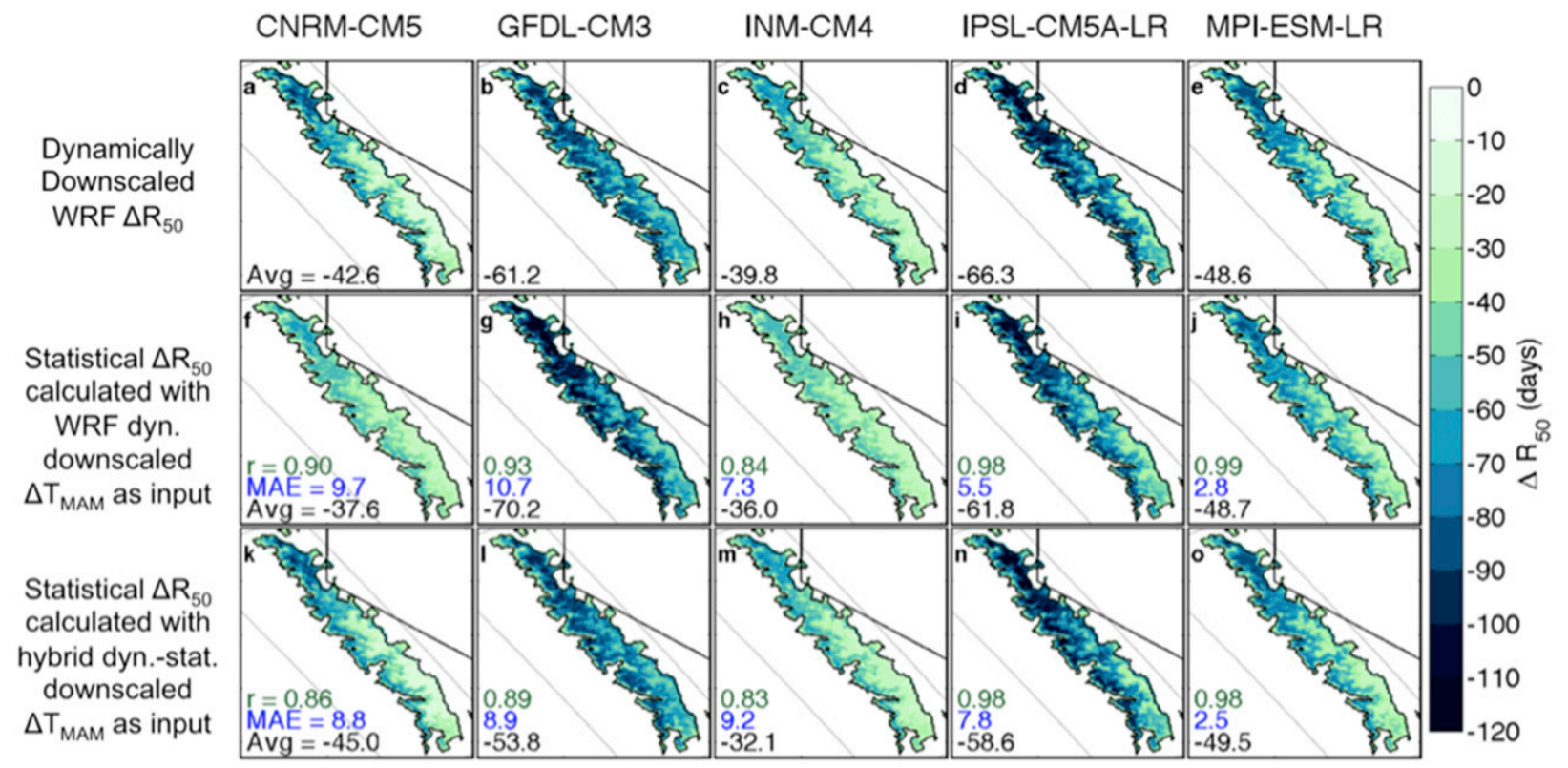

FIG. 4. End-of-twenty-first-century change (WY $2092-2101$ average minus $\mathrm{WY}_{1992-2001}$ average) in $R_{50}$ (days) under the RCP8.5 emissions scenario for CNRM-CM5, GFDL CM3, INM-CM4.0, IPSL-CM5A-LR, and MPI-ESM-LR produced from three methods: (a)-(e) Dynamically downscaled WRF output, (f)-(j) statistical projection using dynamically downscaled WRF spring near-surface warming $\Delta T_{\text {MAM }}$ as input, and (k)-(o) statistical projection using W2017's hybrid dynamical-statistical downscaled $\Delta T_{\text {MAM }}$ as input. Results are shown for locations with climatological baseline $R_{50}$ on or after 1 March, and green through blue shades represent advances in $R_{50}$. Black text shows domain-average in $R_{50}$. Blue text in (f)-(o) denotes the mean absolute error compared to (a)-(e). Green text in (f)-(o) denotes the spatial correlation with (a)-(e) for each GCM. 


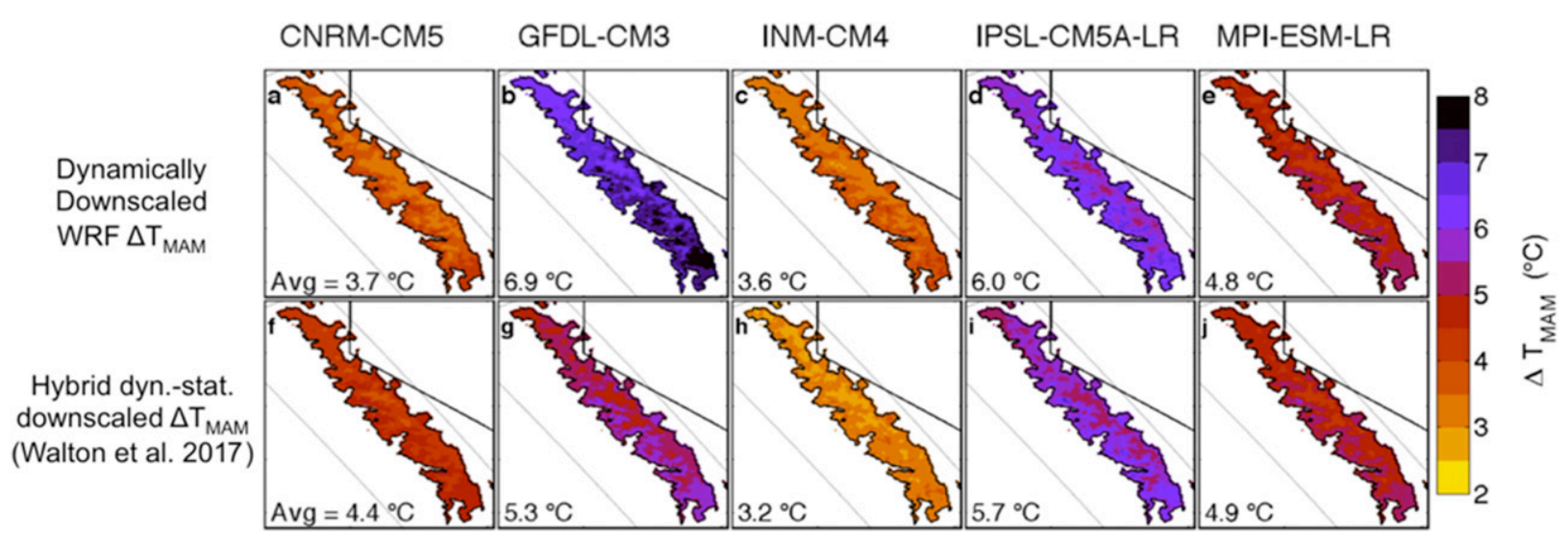

FIG. 5. End-of-twenty-first-century change in near-surface temperature averaged over March-May $\Delta T_{\mathrm{MAM}}\left({ }^{\circ} \mathrm{C}\right)$ under the RCP8.5 forcing scenario for CNRM-CM5, GFDL CM3, INM-CM4.0, IPSL-CM5A-LR, and MPI-ESM-LR. (a)-(e) WRF dynamically downscaled output. (f)-(j) Hybrid dynamical-statistical downscaled output from W2017. Black text shows domain-average $\Delta T_{\text {MAM }}$.

For all dynamically downscaled GCMs, advances in mean $R_{50}$ tend to be greater on western-facing mountain slopes. This spatial pattern can be explained by mean near-surface $(2 \mathrm{~m})$ springtime (March-May) warming projections $\Delta T_{\text {MAM }}$. Figures $5 \mathrm{a}-\mathrm{e}$ present WRF dynamically downscaled end-of-twenty-firstcentury $\Delta T_{\text {MAM }}$ under RCP8.5. For each of the five GCMs, somewhat stronger warming is projected on the western-facing mountain slopes near the springtime freezing line. These regions have the strongest SAF (W2017) and greatest 1 April snow water equivalent (SWE) loss (Sun et al. 2017, manuscript submitted to Nat. Climate Change). This warming leads to decreases in annual-mean $S / P$ and earlier snowmelt, which together result in large advances in mean $R_{50}$ in those areas. Another feature of the spatial patterns of $R_{50}$ advances is relatively small changes at the highest elevations in the southern $\mathrm{SN}$, which is consistent with previous findings of high-elevation snowpack in California (Sun et al. 2016). Despite significant future warming (W2017), these areas remain well above the freezing line during the accumulation season. As a result, changes to $S / P$ and snow accumulation are small at the highest elevations, and the weak advances in $R_{50}$ (10-20 days) at those locations are primarily due to earlier snowmelt.

Intermodel differences in $\Delta R_{50}$ can largely be explained by differences in $\Delta T_{\mathrm{MAM}}$, as $\Delta R_{50}$ appears to be strongly negatively related to $\Delta T_{\mathrm{MAM}}$. GFDL CM3 and IPSL-CM5A-LR project large $\Delta T_{\text {MAM. Domain- }}$ average spring warmings are $6.0^{\circ}$ and $6.9^{\circ} \mathrm{C}$, respectively, and some locations warm more than $7^{\circ} \mathrm{C}$. This strong warming explains the sizable advances in mean $R_{50}$ for GFDL CM3 and IPSL-CM5A-LR. Weaker $\Delta T_{\text {MAM }}$ in INM-CM4.0 and CNRM-CM5 (domain-average $3.6^{\circ}$ and $3.7^{\circ} \mathrm{C}$, respectively) corresponds to smaller mean $R_{50}$ advances. (MPI-ESM-LR is moderate in both $\Delta T_{\text {MAM }}$ and $\Delta R_{50}$.) This link suggests $\Delta T_{\text {MAM }}$ might be a reasonable predictor for $\Delta R_{50}$, a hypothesis that will be explored in the description of the statistical $\Delta R_{50}$ model in section 3. In section 3, we also consider mean $P$ changes as a predictor for $\Delta R_{50}$. However, $P$ timing hardly changes in the downscaled WRF simulations, so intermodel differences in $R_{50}$ advances are likely not attributable to $P$ changes, as we will show.

\section{3. $\Delta \boldsymbol{R}_{50}$ statistical model description and evaluation}

The previous section focused on projections of changes to mean $R_{50}$ for only a single time slice, a single forcing scenario, and for only five GCMs. This information is insufficient to fully quantify the range of possible outcomes due to intermodel spread and choice of forcing scenario. To project $\Delta R_{50}$ for all available CMIP5 GCMs and all forcing scenarios, we adopt a hybrid downscaling approach, developing a computationally efficient statistical $\Delta R_{50}$ model that is designed to emulate the dynamical model. In this section, we describe and evaluate this statistical model.

As noted above, there is a negative relationship between WRF $\Delta R_{50}$ (Figs. 4a-e) and $\Delta T_{\text {MAM }}$ (Figs. 5a-e). To quantify this relationship, Fig. 6a shows the correlation coefficient for each grid point between dynamical $\Delta R_{50}$ and $\Delta T_{\mathrm{MAM}}$. The correlation values reflect a blend of intermodel and interannual variability, as they are calculated from annually averaged $\Delta R_{50}$ and $\Delta T_{\mathrm{MAM}}$ values from all five models. This produces a sample size of 50 for each grid point ( 5 models $\times 10$ water years). There is a strong anticorrelation between $\Delta R_{50}$ and 
(a) Correlation between 5-model WRF $\Delta R_{50}$ and WRF $\Delta T_{M A M}$
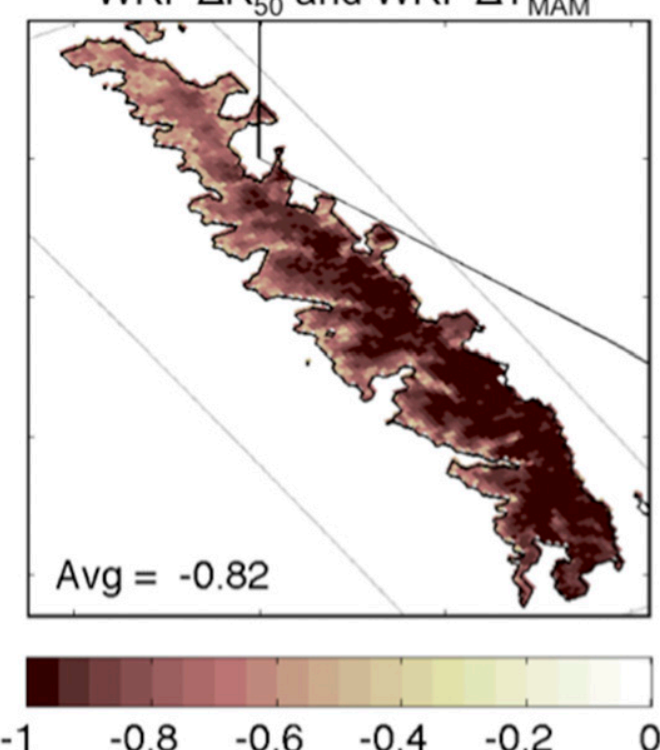

(b) Slope of linear regression of
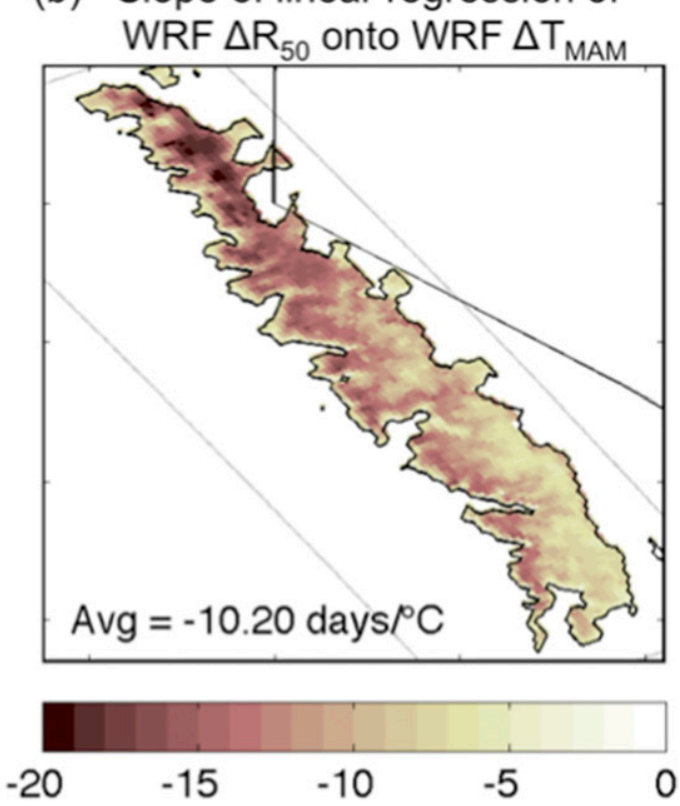

FIG. 6. (a) Correlation coefficient between the five-model dynamically downscaled end-of-twenty-first-century change in $R_{50}$ timing $\Delta R_{50}$ and near-surface March-May warming $\Delta T_{\mathrm{MAM}}$. (b) Slope of the linear regression of the five-model dynamically downscaled $\Delta R_{50}$ onto the five-model dynamically downscaled $\Delta T_{\text {MAM }}$ (days ${ }^{\circ} \mathrm{C}^{-1}$ ). $\mathrm{Black}$ text denotes the domain average value.

$\Delta T_{\mathrm{MAM}}$, with a spatially averaged value of $r=-0.82$. That $\Delta T_{\text {MAM }}$ would be a predictor for $\Delta R_{50}$ is physically sensible, as climatological baseline $R_{50}$ for many mountainous locations falls in March-May (Fig. 2), and March-May runoff accounts for a significant portion of annual runoff throughout much of the SN. Thus, we aim to build a statistical modeling framework that projects $\Delta R_{50}$ given $\Delta T_{\mathrm{MAM}}$. Below, we discuss our choice of $\Delta T_{\mathrm{MAM}}$ as a predictor further, as well as other predictors we considered.

The first step is to linearly regress dynamically downscaled $\Delta R_{50}$ onto dynamically downscaled $\Delta T_{\text {MAM }}$ for each pair of coordinates $(i, j)$ in the 3-km-resolution domain with climatological baseline $R_{50}$ on or after 1 March. As with the corresponding correlation coefficient shown in Fig. 6a, the slope $\alpha$ of this linear regression is determined by intermodel and interannual variability, that is, 50 data points $(10$ water years $\times$ 5 models) for each $(i, j)$ pair. Figure $6 \mathrm{~b}$ presents the spatial pattern of $\alpha$, the average expected advance in mean $R_{50}$ timing per degree of March-May near-surface warming. In calculating $\alpha$, we force the linear relationship to go through $(0,0)$, that is, it has no intercept and an expression that a strong change in $R_{50}$ timing is unlikely without a change in $T_{\text {MAM }}$. The domain-average $\alpha$ is -10.2 days ${ }^{\circ} \mathrm{C}^{-1}$, but the northern $\mathrm{SN}$ and midelevation western slopes are much more sensitive, with projected $R_{50}$ changes of more than -19 days ${ }^{\circ} \mathrm{C}^{-1}$. The strong sensitivity at these midelevation locations is due to both warming-driven $S / P$ decreases and earlier snowmelt, which conspire to advance $R_{50}$. The sensitivity at higher elevations is lower because the $T_{\text {MAM }}$ increases lead mostly just to earlier snowmelt. Moreover, these more sensitive regions correspond well to regions of greatest projected 1 April SWE decreases (Sun et al. 2016) and greatest SAF-enhanced warming and snow cover loss (W2017). After determining $\alpha$, we then predict $\Delta R_{50}$ with the following equation:

$$
\Delta R_{50, \mathrm{GCM}, i, j} \cong \alpha_{i, j} \times \Delta T_{\mathrm{MAM}, \mathrm{GCM}, i, j}
$$

It is possible to evaluate the realism of $\alpha$ as simulated by the dynamical model. The relationship between purely interannual $R_{50}$ and $T_{\mathrm{MAM}}$ anomalies is linear to a good approximation in both observations and the WRF simulation. Figure 7 presents a scatterplot of observed annual $T_{\mathrm{MAM}}$ anomalies versus $R_{50}$ anomalies over WY $Y_{1916-2014}$. Observed interannual $R_{50}$ and $T_{\text {MAM }}$ variations in California are anticorrelated $(r=-0.67)$. The observed linear sensitivity of $\mathrm{WY}_{1916-2014} R_{50}$ to $T_{\text {MAM }}$ is -9.46 days ${ }^{\circ} \mathrm{C}^{-1}$. In WRF, the domain-average slope of the linear regression of $\mathrm{WY}_{1992-2001} R_{50}$ onto $T_{\text {MAM }}$ is -11.4 days ${ }^{\circ} \mathrm{C}^{-1}$ (close to the domain-average $\alpha$ of -10.2 days ${ }^{\circ} \mathrm{C}^{-1}$ ). 


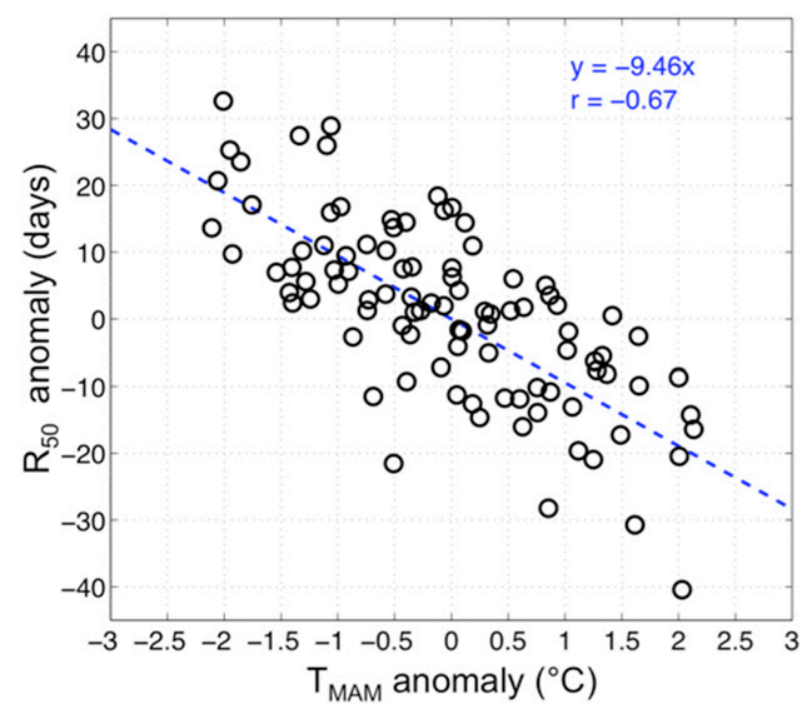

FIG. 7. Scatterplot of observed near-surface temperature anomalies $\left({ }^{\circ} \mathrm{C}\right)$ averaged over March-May $T_{\text {MAM }}$ and observed $R_{50}$ anomalies (days) over WY $\mathrm{W}_{1916-2014}$. The blue line is the linear regression of $\mathrm{WY}_{1916-2014} R_{50}$ onto $T_{\mathrm{MAM}}$. Blue text denotes the slope of this linear regression as well as the correlation coefficient. The $T_{\text {MAM }}$ anomalies are calculated from the NOAA/NCDC nClimDiv statewide temperature database (ftp://ftp.ncdc.noaa.gov/pub/data/ cirs/climdiv/state-readme.txt), which includes monthly mean maximum and minimum temperature aggregated at statewide levels for the United States for January 1895 to the present. Monthly maximum and minimum temperatures are averaged together to calculate monthly mean temperature. The $T_{\text {MAM }}$ anomalies presented here are calculated from the detrended MAM temperature time series for California. The $R_{50}$ anomalies are calculated from the detrended gauge-averaged $R_{50}$ time series from available observations at the 11 USGS HCDN-2009 streamflow gauges in Table 1 (described in section $2 b$ ).

The approximate agreement between observations and the WRF simulation provides crucial support for the realism of the WRF simulation of streamflow timing and a statistical model based on the linear relationships between $\Delta R_{50}$ and $\Delta T_{\mathrm{MAM}}$. This form of model evaluation, focusing on sensitivity parameters key to climate change response, is likely more relevant than the general model evaluation of temporal and spatial variability in streamflow presented in section $2 \mathrm{~b}$. (We note that the range of $T_{\text {MAM }}$ anomalies over $\mathrm{WY}_{1916-2014}$ is small compared to the range of projected $\Delta T_{\mathrm{MAM}}$, and that the linear relationship between $\Delta R_{50}$ and $\Delta T_{\mathrm{MAM}}$ will only hold up to a certain temperature threshold. Because the linear relationship is based on future climate simulations, this is already considered.)

One source of error in the statistical $\Delta R_{50}$ model [Eq. (1)] arises from approximating $\Delta R_{50}$ as a linear function of $\Delta T_{\mathrm{MAM}}$. Though this error source is likely small due to high correlation coefficients between the two variables (Fig. 6a), we can evaluate it by statistically projecting $\Delta R_{50}$ with the dynamically downscaled $\Delta T_{\text {MAM }}$ under RCP8.5 (Figs. 5a-e) as input. Figures $4 \mathrm{f}-\mathrm{j}$ present this statistical $\Delta R_{50}$ projection, which can be compared to dynamically downscaled $\Delta R_{50}$ (Figs. 4a-e). Overall, the approximated values of $\Delta R_{50}$ (Figs. $4 \mathrm{f}-\mathrm{j}$ ) almost perfectly mirror the dynamically downscaled values (Figs. 4a-e). The approximated spatial patterns are highly correlated with their dynamical counterparts $(r>0.84$ for all GCMs). The mean absolute errors (MAEs; calculated by averaging the absolute value of the errors over the region of interest) are less than 11 days for all models, small compared to domain-average advances in $R_{50}$ that range between 39 and 66 days. This comparison lends further credibility to the choice to model $\Delta R_{50}$ as a linear function of $\Delta T_{\text {MAM. }}$.

To apply the statistical $\Delta R_{50}$ model to all GCMs and forcing scenarios, we rely on projections of $\Delta T_{\mathrm{MAM}}$ from W2017. W2017 produced 3-km horizontal resolution monthly near-surface warming projections for our study domain for all available CMIP5 GCMs under forcing scenarios RCP8.5, RCP6.0, RCP4.5, and RCP2.6. W2017 also used a hybrid dynamical-statistical technique to downscale warming that relies on two largescale GCM predictors (regional-mean warming and east-west warming contrast) and a representation of SAF's significant contribution to elevational variations in warming. Figures $5 \mathrm{f}-\mathrm{j}$ present end-of-twenty-firstcentury hybrid downscaled $\Delta T_{\mathrm{MAM}}$ under RCP8.5 from W2017. As discussed in detail in W2017, this method captures the spatial pattern and approximate magnitude of $\Delta T_{\mathrm{MAM}}$ for each of the five dynamically downscaled GCMs (Figs. 5a-e), including the warming enhancement due to SAF at midelevations and in the northern SN.

To assess the error associated with the use of W2017's hybrid downscaled $\Delta T_{\mathrm{MAM}}$ as input to our statistical $\Delta R_{50}$ model, we compare the dynamically downscaled $\Delta R_{50}$ projections under RCP8.5 (Figs. $4 \mathrm{a}-\mathrm{e}$ ) to those calculated by the statistical $\Delta R_{50}$ model [Eq. (1)], now with the hybrid downscaled $\Delta T_{\text {MAM }}$ projections of W2017 as input (Figs. 4k-o). Overall, the spatial correlations between these $\Delta R_{50}$ patterns and WRF's dynamically downscaled patterns are high $(r>0.83)$, and the MAE values are low compared to the magnitude of $\Delta R_{50}$, indicating that the use of hybrid downscaled $\Delta T_{\text {MAM }}$ input reproduces dynamically downscaled $\Delta R_{50}$ projections reasonably well. Still, we note some minor discrepancies. For GFDL CM3, INM-CM4.0, and IPSL-CM5A-LR, hybrid projections of $\Delta T_{\text {MAM }}$ by W2017 (Figs. $5 \mathrm{f}-\mathrm{j}$ ) underestimate the dynamically downscaled $\Delta T_{\text {MAM }}$ somewhat (Figs. 5a-e). As a result, using hybrid downscaled $\Delta T_{\text {MAM }}$ leads to an underestimate of the magnitude of the dynamically 


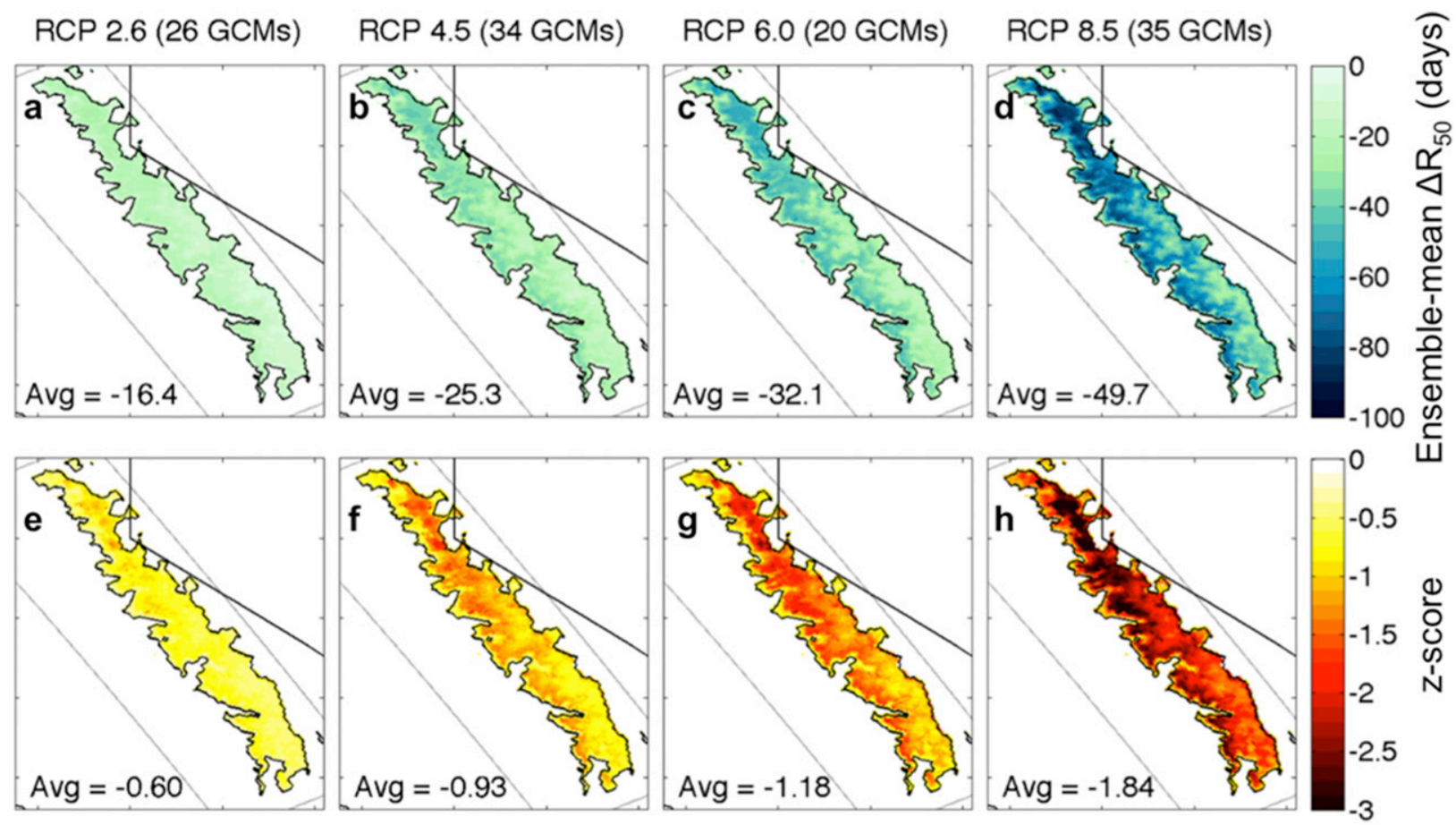

FIG. 8. Ensemble-mean statistical projections of end-of-twenty-first-century change in $R_{50}$ (days) under emissions scenarios (a) RCP2.6, (b) RCP4.5, (c) RCP6.0, and (d) RCP8.5. (e)-(h) The associated $z$ score for the ensemble-mean change in $R_{50}$, which is calculated by dividing the mean $R_{50}$ change by the standard deviation of $R_{50}$ of a 20-yr baseline (WY $\left.\mathrm{W}_{1982-2001}\right)$. Black text denotes the domain average value. The number of GCMs included in the ensemble mean is denoted in the title.

downscaled $\Delta R_{50}$. Similarly, W2017 slightly overestimates $\Delta T_{\text {MAM }}$ for CNRM-CM5 and MPI-ESM-LR, which results in a small overestimation of domainaverage mean $R_{50}$ advances for those GCMs, by +2.4 and +0.9 days, respectively.

Precipitation $P$ changes (especially its seasonality) may also affect future runoff timing, suggesting it ought to be included in our statistical model as a copredictor. Previous studies have found only modest projected changes in mean $P$, which are also small compared to natural variability (Pierce et al. 2013; Cayan et al. 2008; Duffy et al. 2006). Nevertheless, testing was done to include mean wet-season $P$ (December-March) changes as a copredictor along with $\Delta T_{\mathrm{MAM}}$ in the statistical $\Delta R_{50}$ model. Less than $4 \%$ improvement was seen in the model-average MAE, compared to using $\Delta T_{\text {MAM }}$ alone. Additional testing was done to determine if $\Delta T$ or $\Delta P$ averaged over other months produced a more skillful model than one that relies on only $\Delta T_{\mathrm{MAM}}$, but again, no value was gained. Including changes to the 1 April SWE as a copredictor also added no value. Overall, this indicates that advances in $\Delta R_{50}$ are nearly entirely driven by spring warming, consistent with previous studies of observed and projected runoff timing changes over the SN and western United States (e.g., Stewart et al. 2004).
We also note that the dynamical downscaling framework imposes identical interannual variability levels between the baseline and future time slices. Possible changes to interannual variability modes in the twentyfirst century, for example, the El Niño-Southern Oscillation phenomenon (Cai et al. 2014), could impact overall $P$ levels and timing through atmospheric teleconnections, a factor not fully accounted for in GCMs or in this study. However, given the large magnitude of changes in mean runoff timing driven by warming alone, it is difficult to see how our main conclusions would be significantly different if El Niñodriven changes in $P$ do occur.

\section{Results for the full GCM ensemble and all forcing scenarios}

Using the statistical $\Delta R_{50}$ model [Eq. (1)] with the W2017 hybrid downscaled $\Delta T_{\mathrm{MAM}}$ as input, we now generate projections of mean changes in end-of-century $R_{50}$ for all available CMIP5 GCMs under four forcing scenarios: RCP2.6, RCP4.5, RCP6.0, and RCP8.5. Figures $8 \mathrm{a}-\mathrm{d}$ present ensemble-mean changes in $R_{50}$ for RCP2.6, RCP4.5, RCP6.0, and RCP8.5. The spatial patterns of $\Delta R_{50}$ are qualitatively similar for each 
(a) RCP2.6 (26 GCMs)

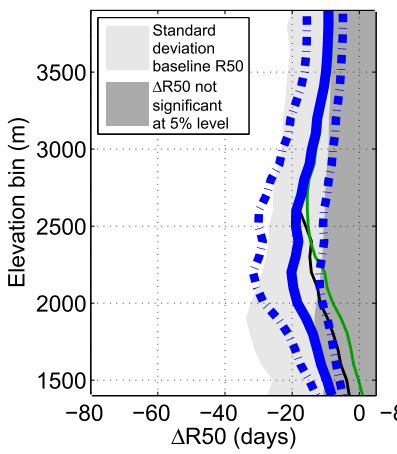

(b) RCP 4.5 (34 GCMs)

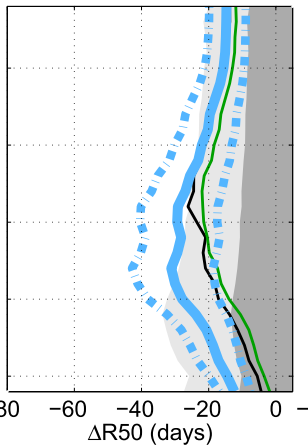

(c) RCP6.0 (20 GCMs)

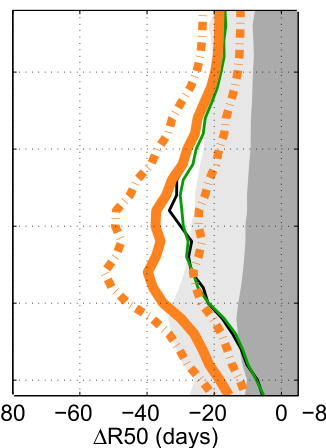

(d) RCP8.5 (35 GCMs)

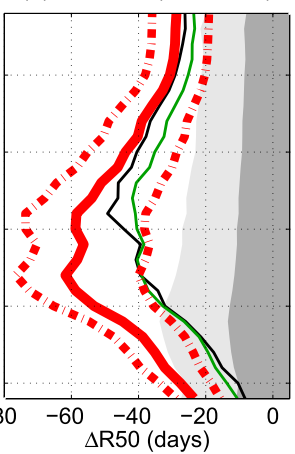

Ensemble-mean $\Delta R 50$ calculated with hybrid downscaled MAM $\triangle T 2$ 10th and 90th percentiles - of GCM distribution based on hybrid downscaled MAM $\triangle T 2$

Ensemble-mean $\Delta R 50$ calc. with BCSD downscaled MAM $\triangle T 2$

Ensemble-mean $\triangle R 50$

downscaled MAM $\triangle T 2$

FIG. 9. Statistical projections of end-of-twenty-first-century change in $R_{50}$ as a function of elevation (binned every $100 \mathrm{~m}$ ) under emissions scenarios RCP2.6, RCP4.5, RCP6.0, and RCP8.5. Solid colored lines represent the ensemble-mean $R_{50}$ change calculated with hybrid dynamical-statistical spring warming as input, while dashed colored lines represent the 10th and 90th percentiles of this GCM distribution. Light gray shading denotes the standard deviation of $R_{50}$ for the extended baseline period (WY 1982-2001). The region outside of the dark gray shading denotes mean changes in $R_{50}$ that are significant at the $5 \%$ level according to a one-tailed $t$ test. Thin black (green) lines represent the ensemble-mean $R_{50}$ change calculated with BCSD-downscaled (BCCA downscaled) spring warming as input. Results are shown for locations with climatological baseline $R_{50}$ on or after 1 Mar. The number of GCMs included in the hybrid-downscaled GCM ensemble is denoted in the title.

forcing scenario, with the magnitudes increasing with forcing scenario strength. While all locations show some advance, the largest are found at elevations between 2000 and $2750 \mathrm{~m}$ and are generally on the western slope of the SN. In some locations, ensemble-mean $R_{50}$ is projected to advance by more than 80 days under RCP8.5. For RCP8.5, the ensemble-mean domain-average $\Delta R_{50}$ is -49.7 days (Fig. $8 \mathrm{~d}$ ), which is close to that of the five-model dynamically downscaled ensemble ( -51.7 days). This supports the idea that the five GCMs we selected for dynamical downscaling approximately represent the GCM ensemble.

Ensemble-mean $R_{50}$ changes are substantial when compared with the interannual variability of the baseline period. To provide a more statistically stable estimate of baseline interannual variability, we extend the baseline simulation to span $\mathrm{WY}_{1982-2001}$. This 20-yr simulation uses the same modeling framework described in section $2 \mathrm{a}$. Figures $8 \mathrm{e}-\mathrm{h}$ present $z$ scores associated with the ensemble-mean changes in $R_{50}$ in Figs. $8 \mathrm{a}-\mathrm{d}$. The $z$ score is calculated by dividing the mean $R_{50}$ change by the standard deviation of $R_{50}$ for the extended baseline period ( $\mathrm{WY}_{1982-2001}$ ), and therefore represents how far outside the baseline $\mathrm{WY}_{1992-2001} R_{50}$ distribution an average future $R_{50}$ is. For all scenarios, the $z$ score indicates a significant shift. Under RCP2.6 and RCP4.5 (Figs. 8e and 8f), for example, the domainaverage ensemble-mean $z$ scores are -0.60 and -0.93 , respectively. Under RCP6.0 (Fig. 8g), the domainaverage ensemble-mean $z$ score $(-1.18)$ translates to a future mean $R_{50}$ equivalent to the 12th percentile of baseline $R_{50}$ distribution. Ensemble-mean $R_{50}$ changes compared to the baseline's interannual variability are dramatic for RCP8.5 (Fig. 8h), as the domain-average $z$ score is -1.84 , approximately the 3 rd percentile of the baseline $R_{50}$ distribution. In fact, under RCP8.5, the ensemble-mean domain-average $R_{50}$ is projected to be earlier than that of any baseline year of the extended baseline simulation. For RCP4.5, RCP6.0, and RCP8.5 especially, the ensemble-mean $R_{50}$ changes correspond to a substantial change in the runoff climatology.

Figure 9 shows the elevational profile of $\Delta R_{50}$ for the ensemble-mean (thick solid line) under the four RCPs. Elevations are binned every $100 \mathrm{~m}$, and $\Delta R_{50}$ for a given elevation bin is the spatial average across grid cells within the bin. Light gray shading represents the standard deviation of $R_{50}$ over $\mathrm{WY}_{1982-2001}$ at each elevation, a measure of interannual variability. Under RCP8.5 (Fig. 9d), ensemble-mean $\Delta R_{50}$ has a greater than one standard deviation advance for all elevations above $1500 \mathrm{~m}$. Ensemble-mean $\Delta R_{50}$ is outside of one standard deviation in the 2000-3100-m elevation band under RCP6.0 (Fig. 9c) and is near or less than one standard deviation for RCP4.5 and RCP2.6 (Figs. 9a and $9 b$ ).

Ensemble projections also allow for the quantification of uncertainty in $R_{50}$ projections due to GCM spread. Thick dashed lines in Fig. 9 represent the 10th and 90th percentiles of the GCM spread in $\Delta R_{50}$ when calculated with hybrid downscaled $\Delta T_{\mathrm{MAM}}$. For all forcing scenarios, GCM spread is greatest in the 2000-3000-m elevation band, which reflects the larger spread in $\Delta T_{\text {MAM }}$ projections at those elevations (W2017). Under RCP8.5, however, despite an intermodel $\Delta R_{50}$ range 
of more than 30 days at some elevations, the advance in $R_{50}$ is well outside one standard deviation of interannual variability for all models in the 2000-3200-m elevation band.

To shed light on the statistical significance of these changes, we perform a one-tailed $t$ test that assesses the likelihood that a $10-y r$ sample with a given mean shift in $R_{50}$ could be drawn from the same population as the baseline $\mathrm{WY}_{1982-2001} R_{50}$ distribution. To do this, we assume the future period is a 20 -yr sample. The sample size is $n=20$, so nineteen degrees of freedom are used. The region outside of the dark gray shading in Fig. 9 represents changes in mean $R_{50}$ timing that are significant at the 5\% level for each elevation. RCP2.6 ensemble-mean changes are significant at the $5 \%$ level in the 1800-3300-m elevation bin, but the changes are not significant for all GCMs. As we discuss in section 6, RCP2.6 is not likely to be a plausible forcing scenario. Under RCP4.5, RCP6.0, and RCP8.5 (Figs. 9b-d), $\Delta R_{50}$ is significantly different at the $5 \%$ level from the baseline mean for all elevations and all GCMs. (A minor exception can be found under RCP4.5 at the lowest elevations for the GCMs giving the least warming.) Under RCP8.5, $\Delta R_{50}$ is significantly different at the $1 \%$ level from the baseline mean for all elevations and all GCMs (not shown). Estimates of recent global greenhouse gas emissions indicate they are closely approaching and possibly exceeding the RCP8.5 pathway (Le Quéré et al. 2015). Should emissions continue to follow RCP8.5, it is therefore very likely that future advances in runoff timing will be dramatically different from internal climate variability at all elevations.

The spatial structure of runoff timing advances also leads to an increase in the spatial homogeneity of $R_{50}$ across the SN. Figures 10a and 10b present the distribution of $R_{50}$ dates for the end of the twentieth century and the end of the twenty-first century under RCP8.5, respectively, binned by 5-day intervals. A striking change in the shape of the distribution is seen. In the baseline (Fig. 10a), $R_{50}$ dates are fairly evenly distributed between the months of March-June, with roughly one-fourth of $R_{50}$ dates occurring in each of those 4 months $(25.9 \%$ in March, $21.0 \%$ in April, $26.5 \%$ in May, and $25.9 \%$ in June). However, there is significantly less diversity in projected end-of-twenty-first-century $R_{50}$ spatial patterns, with over half the grid points having projected $R_{50}$ dates in February (Fig. 10b). Clearly, warming produces a strong tendency for the center of runoff timing to more closely match the center of precipitation timing. We are not aware of any assessment of increasing homogeneity of runoff timing across the SN or other regions with snowmelt-dominated runoff. This
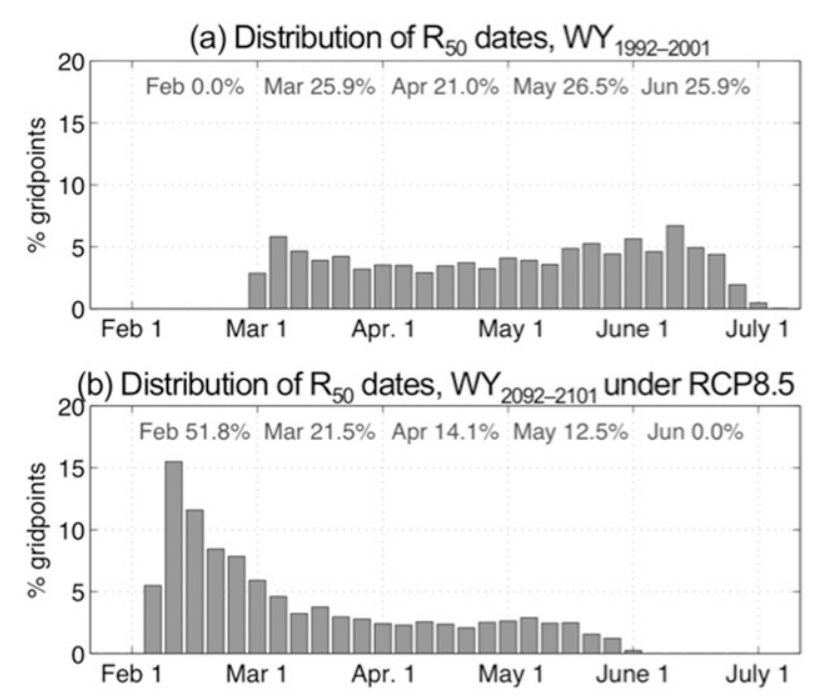

FIG. 10. Distribution of $R_{50}$ dates for (a) the end-of-twentieth-

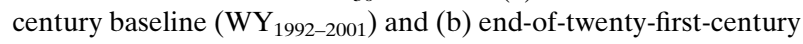
(WY 2092-2101) under RCP8.5. The $R_{50}$ dates are binned in 5-day intervals. We consider grid points with snowmelt-dominated runoff in the baseline, so the distribution is calculated based on grid points within the contoured region in Fig. 2. The distribution of $R_{50}$ dates in (a) is based on the WRF dynamical downscaling simulation; the distribution of $R_{50}$ dates in (b) is based on the 35-model ensemblemean statistical $R_{50}$ projection. Text within each subplot denotes the percent of grid points with $R_{50}$ dates falling in each of the months of February-June.

important consequence of warming must be considered in water resources planning and flood protection.

\section{Importance of snow albedo feedback to $\Delta \boldsymbol{R}_{50}$ projections}

Both WRF dynamically downscaled and hybriddownscaled $\Delta T_{\text {MAM }}$ projections explicitly include warming enhancement due to SAF and its intricate spatial structure (Fig. 5). Through an analysis of changes to the surface energy budget, W2017 demonstrated that SAF is responsible for the finescale warming amplification in regions of future snow cover loss. This mechanism has the largest effect at midelevations, which is also linked to larger runoff timing changes there. Here we quantify the importance of using warming patterns that include $\mathrm{SAF}$ to $\Delta R_{50}$ outcomes. For this exercise, we consider three methods of projecting $\Delta T_{\text {MAM }}$ that do not consider SAF effects in the SN, at least not explicitly: linear interpolation of GCM output, bias correction and constructed analogs (BCCA; Hidalgo et al. 2008; Maurer and Hidalgo 2008), and bias correction with spatial disaggregation (BCSD; Wood et al. 2002, 2004; Maurer 2007). BCCA and BCSD are two commonly used statistical downscaling techniques. Linear interpolation is a 


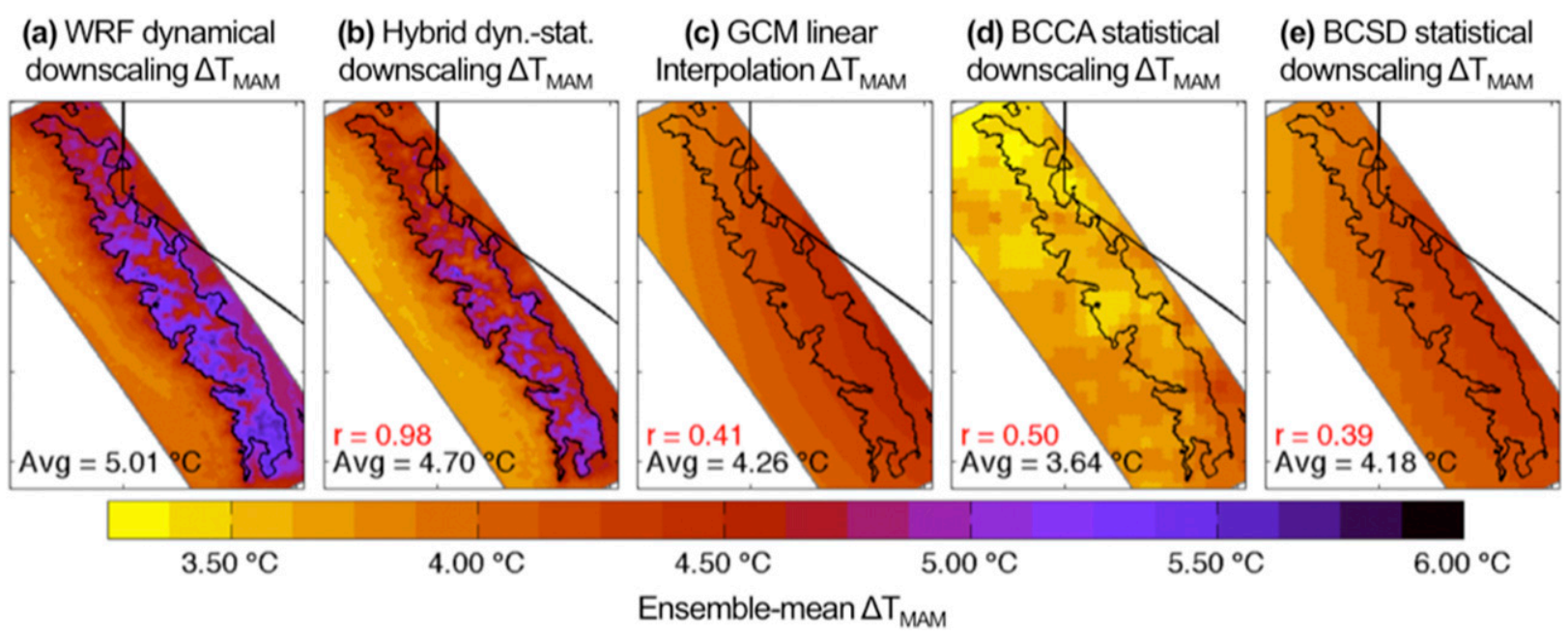

FIG. 11. End-of-twenty-first-century change (WY ${ }_{2092-2101}$ average minus $\mathrm{WY}_{1992-2001}$ average) in near-surface March-May temperature $\Delta T_{\text {MAM }}\left({ }^{\circ} \mathrm{C}\right)$ under the RCP8.5 forcing scenario averaged over five GCMs (CNRM-CM5, GFDL CM3, INM-CM4.0, IPSL-CM5A-LR, and MPI-ESM-LR) downscaled using five methods: (a) WRF dynamical downscaling, (b) W2017's statistical downscaling, (c) linear interpolation, (d) BCCA, and (e) BCSD. Black text denotes domain-average warming within black contoured region. Red text in (b)-(e) denotes the spatial correlation with (a) within the black contoured region.

simple and naïve method of downscaling GCM output that represents a baseline measure of downscaling skill against which the other methods can be compared. BCCA and BCSD $T$ projections were obtained online from the archive of downscaled CMIP3 and CMIP5 climate and hydrology projections (Brekke et al. 2013). BCCA $T$ projections are available as daily maximum and minimum $T$ at $1 / 8^{\circ}$ resolution; we average these together to produce monthly average $T$. Similar processing was applied to BCSD maximum and minimum $T$, which are available as monthly averages.

Figures 11a-e present the end-of-twenty-first-century $\Delta T_{\text {MAM }}$ under RCP8.5 averaged over five GCMs (CNRM-CM5, GFDL CM3, INM-CM4.0, IPSL-CM5ALR, and MPI-ESM-LR) downscaled using five methods: WRF dynamical downscaling, hybrid downscaling, linear interpolation, BCCA, and BCSD. Both dynamical downscaling (Fig. 11a and Figs. 5a-e) and hybrid downscaling (Fig. 11b and Figs. 5f-j) reveal warming amplification due to snow cover loss and SAF at midelevations and in the southern SN. However, warming patterns produced through linear interpolation (Fig. 11c), BCCA (Fig. 11d), and BCSD (Fig. 11e) do not feature such a warming enhancement. We note that warming signals produced through BCSD downscaling are nearly identical to those produced using linear interpolation. This similarity arises because BCSD applies the same bias correction to both the baseline and future time periods. W2017 offers a comprehensive analysis of the different warming patterns that arise through these downscaling methods for this particular domain, adding to a number of studies that compare downscaling methods for other domains (Wood et al. 2004; Maurer and Hidalgo 2008; Gutmann et al. 2012, 2014).

Next, we analyze patterns of runoff timing that arise from the $\Delta R_{50}$ statistical model [Eq. (1)] calculated with the five methods of downscaled $\Delta T_{\text {MAM }}$ in Fig. 11 as input. Figure $12 \mathrm{a}$ presents $\Delta R_{50}$ estimated based on WRF dynamically downscaled $\Delta T_{\text {MAM }}$ averaged over the five GCMs, while Figs. 12b-e show the differences between outcomes in Fig. 12a and those produced with $\Delta T_{\text {MAM }}$ from the other four downscaling methods. Using W2017's hybrid downscaled $\Delta T_{\text {MAM }}$ model as input to the $\Delta R_{50}$ statistical model produces outcomes (Fig. 12b) remarkably similar to those produced with WRF dynamically downscaled $\Delta T_{\text {MAM }}$ as input (domain-average MAE is only 3.03 days). However, $\Delta R_{50}$ outcomes produced using linearly interpolated, BCCA, and BCSD (Figs. 12c-e) $\Delta T_{\text {MAM }}$ systematically underestimate the magnitude of $\Delta R_{50}$ in WRF (Fig. 12a), with domain-average differences of 7.67, 13.97, and 8.41 days, respectively. The differences are greatest in the northern SN and at midelevations on the western slopes, where linear interpolation, BCCA, and BCSD systematically underestimate warming because they do not include warming amplification due to SAF. For example, $\Delta R_{50}$ outcomes produced using BCCA $\Delta T_{\text {MAM }}$ are 20-30 days less than those produced using WRF's $\Delta T_{\text {MAM }}$ at these locations. At the highest elevations $(>3000 \mathrm{~m})$, WRF's $\Delta T_{\text {MAM }}$ (Fig. 11a) roughly agrees with that of linear interpolation (Fig. 11c) and BCSD (Fig. 11e). This approximate agreement in $\Delta T_{\mathrm{MAM}}$ and a 


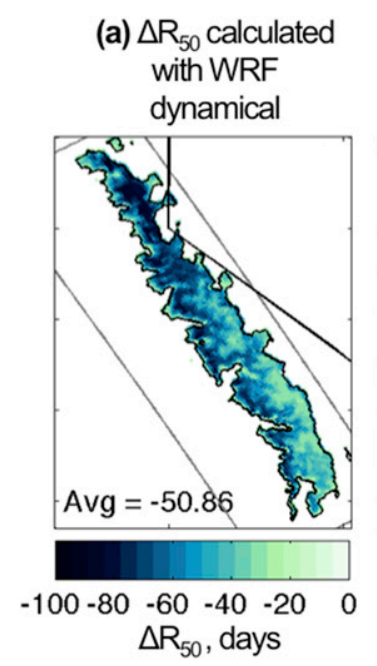

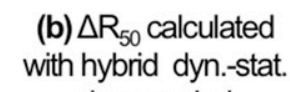
with hybrid dyn.-stat

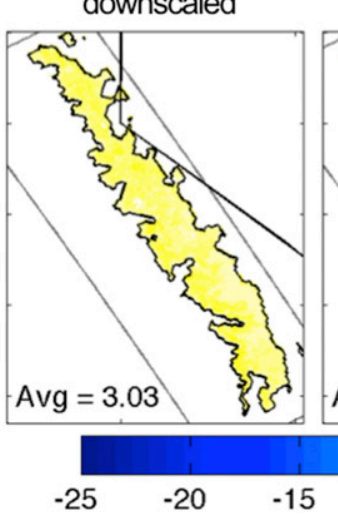
(c) $\Delta R_{50}$ calculated with interpolated GCM

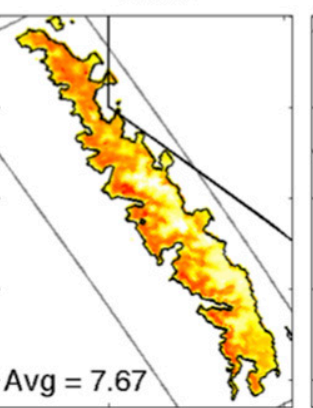

(d) $\triangle R_{50}$ calculated with BCCA stat. downscaled

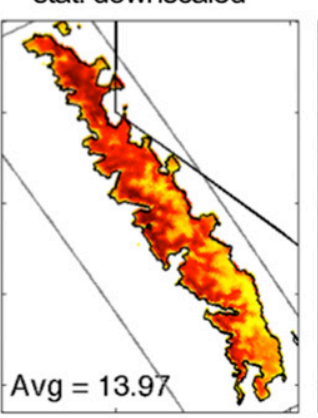

(e) $\Delta R_{50}$ calculated with BCSD stat. downscaled

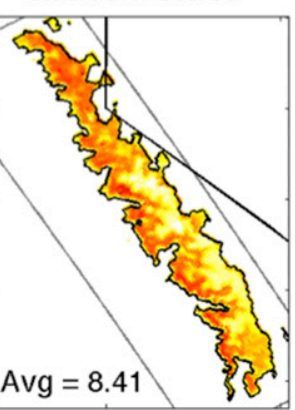

FIG. 12. Statistical projection of end-of-twenty-first-century change in $R_{50}$ (days) under the RCP8.5 forcing scenario calculated with spring warming from (a) WRF dynamical downscaling, (b) hybrid dynamical-statistical downscaling, (c) linear interpolation of GCM output, (d) BCCA statistical downscaling, and (e) BCSD statistical downscaling. Results are averaged over five GCMs (CNRM-CM5, GFDL CM3, INM-CM4.0, IPSL-CM5A-LR, and MPI-ESM-LR). In (b)-(e), (a) is subtracted to highlight differences. Results are shown for locations with climatological baseline $R_{50}$ on or after 1 Mar, and black text denotes domain-average value.

weaker linear sensitivity of $\Delta R_{50}$ to $\Delta T_{\mathrm{MAM}}$ at the highest elevations (Fig. 6b) are the main reasons $\Delta R_{50}$ calculations based on the various datasets of $\Delta T_{\mathrm{MAM}}$ are within 10 days of one another at the highest elevations.

The impact of the downscaling technique is also seen in Fig. 9, where thin black (green) lines show the elevational profile of ensemble-mean $\Delta R_{50}$ calculated with BCSD-downscaled (BCCA downscaled) spring warming as input. As mentioned before, the elevational profile of $\Delta R_{50}$ calculated with BCSD-downscaled spring warming is nearly identical to that produced using linearly interpolated GCM spring warming. For each RCP, using BCSD or BCCA downscaled $\Delta T_{\mathrm{MAM}}$ as input significantly underestimates the magnitude of the $R_{50}$ advance at elevations below $2700 \mathrm{~m}$ compared to that calculated using W2017's hybrid downscaled $\Delta T_{\text {MAM }}$ (solid colored lines). This is partly due to an underestimation of midelevation (2000-2700 m) warming that stems from the inability of BCCA and BCSD to incorporate SAF effects.

Several regional climate adaptation planning agencies and tools rely on BCCA or BCSD downscaled projections. For example, Cal-Adapt (http:// cal-adapt.org/), which was developed based on the 2009 California Climate Adaptation Strategy and provides access to climate data produced by California's scientific community, employs BCSD to downscale $T, P$, and SWE to $1 / 8^{\circ}$ spatial resolution. Though BCCA and BCSD do not directly simulate runoff timing, their $T, P$, and SWE projections can serve as input to a hydrologic or land surface model (such as Noah-MP) to simulate runoff and estimate the sensitivity of runoff timing to spring temperature. Because SAF is very likely a key feature of future warming in the $\mathrm{SN}$, hydroclimate projections based on BCSD/BCCA are associated with an underestimation of future runoff timing advances, especially at midelevations.

\section{Summary and implications}

We develop a statistical model for the date in the water year by which $50 \%$ of the cumulative surface runoff has occurred $\left(R_{50}\right)$ and create multimodel, multiscenario projections of high-resolution changes to Sierra Nevada runoff timing for the end of the twentyfirst century. Projections are based on linear relationships between end-of-twenty-first-century springtime warming and runoff timing changes according to five dynamically downscaled GCMs. These linear relationships are comparable to those found in observations. Hybrid downscaled $T$ that explicitly accounts for SAF (W2017) is then used to project runoff timing changes for all GCMs under forcing scenarios RCP2.6, RCP4.5, RCP6.0, and RCP8.5. Evaluation of the statistical model for runoff timing projections shows that it is able to successfully reproduce dynamical solutions and can credibly produce outcomes for any GCM given only its regionalized spring warming.

Projections reveal that future warming in the Sierra Nevada leads to strong shifts toward more liquid precipitation and earlier snowmelt. Together, these hydroclimatic changes significantly advance surface runoff, 
particularly at midelevations (2000-2750 m). Advances in $R_{50}$ of over 80 days are projected at some midelevation locations in the 35-model ensemble mean under RCP8.5. Strong $R_{50}$ advances are projected at midelevations even for a forcing scenario associated with curtailed greenhouse gas emissions (RCP4.5), where ensemble-mean $R_{50}$ advances in the 2000-2750-m elevation band are nearly 40 days. The larger changes at midelevations are driven in part by SAF. The absence of this mechanism in other downscaled data products implies a significant underestimate of runoff timing changes at these elevations.

Given estimates of recent global greenhouse gas emissions (Le Quéré et al. 2015), RCP2.6 involves greenhouse gas reductions that have not occurred since the RCP forcing scenarios were created in 2005. The reductions associated with RCP2.6 in the coming decades are likewise unlikely to occur. Thus, we only consider RCP4.5, RCP6.0, and RCP8.5 to be the plausible forcing scenarios. With the minor exception of a few GCMs at elevations below 1800-m under RCP4.5, $R_{50}$ advances are significant at the $5 \%$ level for all elevations for all GCMs and all three of these forcing scenarios (Fig. 9). Therefore, detectable changes in runoff timing in the $\mathrm{SN}$ are inevitable.

In addition to testing the statistical significance of $R_{50}$ advances, we compare the magnitude of $R_{50}$ changes to the standard deviation of interannual variations in $R_{50}$ in the baseline period to assess their climatic significance. Under RCP4.5, ensemble-mean $R_{50}$ advances in the 2000-2750-m elevation band are greater than one standard deviation of baseline interannual variability at midelevations and are nearly one standard deviation elsewhere (Fig. 9b). Thus, even when greenhouse gas emissions are curtailed, the runoff change is climatically significant. For RCP8.5, ensemble-mean $R_{50}$ advances are roughly two standard deviations of baseline interannual variability at midelevations and greater than one standard deviation elsewhere (Fig. 9d). Thus, if greenhouse gas emissions continue unabated, a truly dramatic change in surface hydrology is anticipated by century's end. It is important to keep in mind that the dramatic advances in $R_{50}$ timing examined here are at the level of individual grid points in the regional model and that information about $R_{50}$ changes at streamflow gauges or the watershed level is beyond the scope of this study.

Another important finding of this study is that our projected $R_{50}$ advances are much larger (especially at elevations below $2700 \mathrm{~m}$ ) than those implied by other commonly used downscaled data warming products (e.g., BCCA and BCSD), because these other downscaling methods miss crucial warming amplification due to SAF. Additionally, we find one new consequence of warming-driven advances in runoff timing - an increase in the homogeneity of runoff timing dates across the SN.

Significant and inevitable runoff timing advances have major implications for California's water resource infrastructure. The current infrastructure assumes SN snowpack melts gradually throughout the dry season, and it is unclear whether it can accommodate such drastic changes to runoff timing. Reservoir operational rule curves specify the monthly target water level for each reservoir and are crucial for both flood control/protection and storage. The rule curves were developed in the mid1900s when most of California's dams were built, and the historical data used to inform them generally reflect the hydroclimate of the first half of the twentieth century (Willis et al. 2011). Given significant changes to snowmelt runoff timing found in this study, at a minimum it will be necessary to revise rule curves to avoid detrimental and wasteful water releases. It may also be necessary to find alternative storage, such as in groundwater reservoirs. Changes to runoff timing will also have important consequences for water rights tied to specific seasons or months. Last, shifts in runoff timing have implications beyond California's water resources, including for aquatic ecosystem vitality, soil moisture change in riparian areas, and recreational activities throughout the SN. Long-term climate and streamflow observations throughout the Sierra Nevada will continue to be crucial for constraining uncertainty in future runoff timing projections and for the detection and attribution of anthropogenic runoff timing changes.

Acknowledgments. Funding for this work was provided by the Metabolic Studio in partnership with the Annenberg Foundation (Grant 12-469: Climate Change Projections in the Sierra Nevada) and the U.S. Department of Energy (Grant DE-SC0014061: Developing Metrics to Evaluate the Skill and Credibility of Downscaling).

\section{REFERENCES}

Aguado, E., D. Cayan, L. Riddle, and M. Roos, 1992: Climatic fluctuations and the timing of West Coast streamflow. J. Climate, 5, 1468-1483, https://doi.org/10.1175/15200442(1992)005<1468:CFATTO > 2.0.CO;2.

Arritt, R. W., and M. Rummukainen, 2011: Challenges in regionalscale climate modeling. Bull. Amer. Meteor. Soc., 92, 365-368, https://doi.org/10.1175/2010BAMS2971.1.

Ashfaq, M., S. Ghosh, S.-C. Kao, L. C. Bowling, P. Mote, D. Touma, S. A. Rauscher, and N. S. Diffenbaugh, 2013: Near-term acceleration of hydroclimatic change in the western U.S. J. Geophys. Res. Atmos., 118, 10 676-10 693, https://doi.org/10.1002/jgrd.50816.

Brekke, L., and Coauthors, 2013: Downscaled CMIP3 and CMIP5 climate and hydrology projections: Release of downscaled 
CMIP5 climate projections, comparison with preceding information, and summary of user needs. U.S. Department of the Interior, Bureau of Reclamation, Technical Services Center, Tech. Rep., 104 pp., https://gdo-dcp.ucllnl.org/downscaled_ cmip_projections/techmemo/downscaled_climate.pdf.

Cabré, M., S. A. Solman, and M. N. Nuñez, 2010: Creating regional climate change scenarios over southern South America for the 2020's and 2050's using the pattern scaling technique: Validity and limitations. Climatic Change, 98, 449-469, https://doi.org/ 10.1007/s10584-009-9737-5.

Cai, W., and Coauthors, 2014: Increasing frequency of extreme El Niño events due to greenhouse warming. Nat. Climate Change, 4, 111-116, https://doi.org/10.1038/nclimate2100.

Caldwell, P. M., H.-N. S. Chin, D. C. Bader, and G. Bala, 2009: Evaluation of a WRF dynamical downscaling simulation over California. Climatic Change, 95, 499-521, https://doi.org/ 10.1007/s10584-009-9583-5.

Cayan, D. R., M. D. Dettinger, S. A. Kammerdiener, J. M. Caprio, and D. H. Peterson, 2001: Changes in the onset of spring in the western United States. Bull. Amer. Meteor. Soc., 82, 399-416, https://doi. org/10.1175/1520-0477(2001)082<0399:CITOOS >2.3.CO;2.

— - E. P. Maurer, M. D. Dettinger, M. Tyree, and K. Hayhoe, 2008: Climate change scenarios for the California region. Climatic Change, 87 (Suppl.), 21-42, https://doi.org/10.1007/ s10584-007-9377-6.

Dettinger, M. D., and D. R. Cayan, 1995: Large-scale atmospheric forcing of recent trends toward early snowmelt runoff in California. J. Climate, 8, 606-623, https://doi.org/ 10.1175/1520-0442(1995)008<0606:LSAFOR > 2.0.CO;2.

Dudhia, J., 1989: Numerical study of convection observed during the winter monsoon experiment using a mesoscale twodimensional model. J. Atmos. Sci., 46, 3077-3107, https://doi. org/10.1175/1520-0469(1989)046<3077:NSOCOD>2.0.CO;2.

Duffy, P. B., and Coauthors, 2006: Simulations of present and future climates in the western United States with four nested regional climate models. J. Climate, 19, 873-895, https://doi.org/10.1175/ JCLI3669.1.

Giorgi, F., C. S. Brodeur, and G. T. Bates, 1994: Regional climate change scenarios over the United States produced with a nested regional climate model. J. Climate, 7, 375-399, https://doi.org/ 10.1175/1520-0442(1994)007<0375:RCCSOT>2.0.CO;2.

Gutmann, E. D., R. M. Rasmussen, C. Liu, K. Ikeda, D. J. Gochis, M. P. Clark, J. Dudhia, and G. Thompson, 2012: A comparison of statistical and dynamical downscaling of winter precipitation over complex terrain. J. Climate, 25, 262-281, https://doi.org/10.1175/2011JCLI4109.1.

, T. Pruitt, M. P. Clark, L. Brekke, J. R. Arnold, D. A. Raff, and R. M. Rasmussen, 2014: An intercomparison of statistical downscaling methods used for water resource assessments in the United States. Water Resour. Res., 50, 7167-7186, https://doi.org/10.1002/2014WR015559.

Hara, M., T. Yoshikane, H. Kawase, and F. Kimura, 2008: Estimation of the impact of global warming on snow depth in Japan by the pseudo-global-warming method. Hydrol. Res. Lett., 2, 61-64, https://doi.org/10.3178/hrl.2.61.

Hayhoe, K., and Coauthors, 2004: Emissions pathways, climate change, and impacts on California. Proc. Natl. Acad. Sci. USA, 101, 12 422-12 427, https://doi.org/10.1073/pnas.0404500101.

Hidalgo, H. G., M. D. Dettinger, and D. R. Cayan, 2008: Downscaling with constructed analogues: Daily precipitation and temperature fields over the Unites States. California Energy Commission Tech. Rep. CEC-500-2007$123,48 \mathrm{pp}$.
— - and Coauthors, 2009: Detection and attribution of streamflow timing changes to climate change in the western United States. J. Climate, 22, 3838-3855, https://doi.org/10.1175/2009JCLI2470.1.

Kain, J. S., and J. M. Fritsch, 1990: A one-dimensional entraining/ detraining plume model and its application in convective parameterization. J. Atmos. Sci., 47, 2784-2802, https://doi.org/ 10.1175/1520-0469(1990)047\%3C2784:AODEPM\%3E2.0.CO;2.

Kawase, H., T. Yoshikane, M. Hara, F. Kimura, T. Yasunari, B. Ailikun, H. Ueda, and T. Inoue, 2009: Intermodel variability of future changes in the Baiu rainband estimated by the pseudo global warming downscaling method. J. Geophys. Res., 114, D24110, https://doi.org/10.1029/2009JD011803.

Kim, J., and S. Jain, 2010: High-resolution streamflow trend analysis applicable to annual decision calendars: A western United States case study. Climatic Change, 102, 699-707, https://doi. org/10.1007/s10584-010-9933-3.

Le Quéré, C., and Coauthors, 2015: Global carbon budget 2014. Earth Syst. Sci. Data, 7, 47-85, https://doi.org/10.5194/essd-7-47-2015.

Leung, L. R., Y. Qian, X. Bian, W. M. Washington, J. Han, and J. O. Roads, 2004: Mid-century ensemble regional climate change scenarios for the western United States. Climatic Change, 62 , 75-113, https://doi.org/10.1023/B:CLIM.0000013692.50640.55.

Lins, H. F., 2012: USGS Hydro-Climatic Data Network 2009 (HCDN-2009). U.S. Geological Survey Fact Sheet 2012-3047, 4 pp., http://pubs.usgs.gov/fs/2012/3047.

Maurer, E. P., 2007: Uncertainty in hydrologic impacts of climate change in the Sierra Nevada, California, under two emissions scenarios. Climatic Change, 82, 309-325, https://doi.org/ 10.1007/s10584-006-9180-9.

_ , and H. G. Hidalgo, 2008: Utility of daily vs. monthly largescale climate data: An intercomparison of two statistical downscaling methods. Hydrol. Earth Syst. Sci., 12, 551-563, https://doi.org/10.5194/hess-12-551-2008.

McCabe, G., and M. Clark, 2005: Trends and variability in snowmelt runoff in the western United States. J. Hydrometeor., 6 , 476-482, https://doi.org/10.1175/JHM428.1.

Mesinger, F., and Coauthors, 2006: North American Regional Reanalysis. Bull. Amer. Meteor. Soc., 87, 343-360, https://doi.org/ 10.1175/BAMS-87-3-343.

Mlawer, E. J., S. J. Taubman, P. D. Brown, M. J. Iacono, and S. A. Clough, 1997: Radiative transfer for inhomogeneous atmospheres: RRTM, a validated correlated-k model for the longwave. J. Geophys. Res., 102, 16 663-16 682, https://doi.org/ 10.1029/97JD00237.

Moore, J. N., J. T. Harper, and M. C. Greenwood, 2007: Significance of trends toward earlier snowmelt turnoff, Columbia and Missouri Basin headwaters, western United States. Geophys. Res. Lett., 34, L16402, https://doi.org/10.1029/2007GL031022.

Nakanishi, M., and H. Niino, 2006: An improved Mellor-Yamada level-3 model: Its numerical stability and application to a regional prediction of advection fog. Bound.-Layer Meteor., 119, 397-407, https://doi.org/10.1007/s10546-005-9030-8.

Nakićenović, N., and R. Swart, Eds., 2000: Special Report on Emissions Scenarios. Cambridge University Press, 570 pp.

Niu, G.-Y., and Coauthors, 2011: The community Noah land surface model with multiparameterization options (Noah-MP): 1. Model description and evaluation with local-scale measurements. J. Geophys. Res., 116, D12109, https://doi.org/10.1029/ 2010JD015139.

Pal, J. S., and Coauthors, 2007: Regional climate modeling for the developing world: The ICTP RegCM3 and RegCNET. Bull. Amer. Meteor. Soc., 88, 1395-1409, https://doi.org/10.1175/ BAMS-88-9-1395. 
Pierce, D. W., and Coauthors, 2013: Probabilistic estimates of future changes in California temperature and precipitation using statistical and dynamical downscaling. Climate Dyn., 40, 839-856, https://doi.org/10.1007/s00382-012-1337-9.

Rasmussen, R., and Coauthors, 2011: High-resolution coupled climate runoff simulations of seasonal snowfall over Colorado: A process study of current and warmer climate. J. Climate, 24, 3015-3048, https://doi.org/10.1175/2010JCLI3985.1.

Rauscher, S. A., J. S. Pal, N. S. Diffenbaugh, and M. M. Benedetti, 2008: Future changes in snowmelt-driven runoff timing over the western US. Geophys. Res. Lett., 35, L16703, https://doi.org/ 10.1029/2008GL034424.

Regonda, S. K., B. Rajagopalan, M. Clark, and J. Pitlick, 2005: Seasonal cycle shifts in hydroclimatology over the western United States. J. Climate, 18, 372-384, https://doi.org/10.1175/ JCLI-3272.1.

Salathé, E. P., Jr., R. Steed, C. F. Mass, and P. H. Zahn, 2008: A high-resolution climate model for the U.S. Pacific Northwest: Mesoscale feedbacks and local responses to climate change. J. Climate, 21, 5708-5726, https://doi.org/10.1175/ 2008JCLI2090.1.

— L L. R. Leung, Y. Qian, and Y. Zhang, 2010: Regional climate model projections for the state of Washington. Climatic Change, 102, 51-75, https://doi.org/10.1007/s10584-010-9849-y.

Schär, C., C. Frei, D. Lüthi, and H. C. Davies, 1996: Surrogate climate-change scenarios for regional climate models. Geophys. Res. Lett., 23, 669-672, https://doi.org/10.1029/ 96GL00265.

Skamarock, W. C., and Coauthors, 2008: A Description of the Advanced Research WRF version 3. NCAR Tech. Note NCAR/ TN-475+STR, 113 pp., https://doi.org/10.5065/D68S4MVH.

Slack, J. R., A. M. Lumb, and J. M. Landwehr, 1993: Hydro-climatic Data Network (HCDN): A U.S. Geological Survey streamflow data set for the United States for the study of climate variation, 1874-1988. USGS Water Resource Investigations Rep. 93-4076, CD-ROM.

Snyder, M. A., J. L. Bell, L. C. Sloan, P. B. Duffy, and B. Govindasamy, 2002: Climate responses to a doubling of atmospheric carbon dioxide for a climatically vulnerable region. Geophys. Res. Lett., 29, 1514, https://doi.org/10.1029/2001GL014431.

Stewart, I. T., D. R. Cayan, and M. D. Dettinger, 2004: Changes in snowmelt runoff timing in western North America under a 'business as usual' climate change scenario. Climatic Change, 62 , 217-232, https://doi.org/10.1023/B:CLIM.0000013702.22656.e8.

$-\ldots, \ldots$, and -2005 : Changes toward earlier streamflow timing across western North America. J. Climate, 18 1136-1155, https://doi.org/10.1175/JCLI3321.1.

Sun, F., A. Hall, M. Schwartz, D. Walton, and N. Berg, 2016: Twentyfirst-century snowfall and snowpack changes over the Southern
California mountains. J. Climate, 29, 91-110, https://doi.org/ 10.1175/JCLI-D-15-0199.1.

Taylor, K. E., R. J. Stouffer, and G. A. Meehl, 2012: An overview of CMIP5 and the experiment design. Bull. Amer. Meteor. Soc., 93, 485-498, https://doi.org/10.1175/BAMS-D-11-00094.1.

Tebaldi, C., R. L. Smith, D. Nychka, and L. O. Mearns, 2005: Quantifying uncertainty in projections of regional climate change: A Bayesian approach to the analysis of multimodel ensembles. J. Climate, 18, 1524-1540, https://doi.org/10.1175/JCLI3363.1.

Thompson, G., P. R. Field, R. M. Rasmussen, and W. D. Hall, 2008: Explicit forecasts of winter precipitation using an improved bulk microphysics scheme. Part II: Implementation of a new snow parameterization. Mon. Wea. Rev., 136, 5095-5115, https://doi.org/10.1175/2008MWR2387.1.

Timbal, B., A. Dufour, and B. McAvaney, 2003: An estimate of future climate change for western France using a statistical downscaling technique. Climate Dyn., 20, 807-823, https:// doi.org/10.1007/s00382-002-0298-9.

USDA Forest Service, 2009: The importance of streamflow in California's southern Sierra Nevada mountains: Kings River Experimental Watersheds. Pacific Southwest Research Station, Forest Service, U.S. Department of Agriculture, 2 pp., http:// www.fs.fed.us/psw/topics/water/kingsriver/documents/ brochures_handouts/Stream_Discharge_PUBLIC.pdf.

van Vuuren, D. P., and Coauthors, 2011: The representative concentration pathways: An overview. Climatic Change, 109, 5-31, https://doi.org/10.1007/s10584-011-0148-z.

Walton, D. W., A. Hall, N. Berg, M. Schwartz, and F. Sun, 2017: Incorporating snow albedo feedback into downscaled temperature and snow cover projections for California's Sierra Nevada. J. Climate, 30, 1417-1438, https://doi.org/10.1175/ JCLI-D-16-0168.1.

Wenger, S. J., C. H. Luce, A. F. Hamlet, D. J. Isaak, and H. M. Neville, 2010: Macroscale hydrologic modeling of ecologically relevant flow metrics. Water Resour. Res., 46, W09513, https:// doi.org/10.1029/2009WR008839.

Willis, A. D., J. R. Lund, E. S. Townsley, and B. A. Faber, 2011: Climate change and flood operations in the Sacramento Basin, California. San Francisco Estuary Watershed Sci., 9, 3, https:// doi.org/10.15447/sfews.2011v9iss2art3.

Wood, A. W., E. P. Maurer, A. Kumar, and D. P. Lettenmaier, 2002: Long-range experimental hydrologic forecasting for the eastern United States. J. Geophys. Res., 107, 4429, https://doi.org/ 10.1029/2001JD000659.

—_, L. R. Leung, V. Sridhar, and D. P. Lettenmaier, 2004: Hydrologic implications of dynamical and statistical approaches to downscaling climate model outputs. Climatic Change, 62, 189-216, https://doi.org/10.1023/ B:CLIM.0000013685.99609.9e. 